\title{
Spatial and Seasonal Distributions of Frontal Activity over the French Continental Shelf in the Bay of Biscay
}

\author{
Yelekçi Ozge ${ }^{1,{ }^{*}}$, Charria Guillaume ${ }^{1}$, Capet Xavier ${ }^{2}$, Reverdin Gilles ${ }^{2}$, Sudre Joël ${ }^{3}$, Yahia Hussein ${ }^{4}$ \\ ${ }^{1}$ IFREMER, Univ. Brest, CNRS, IRD, Laboratoire d'Océanographie Physique et Spatiale (LOPS), IUEM, \\ F-29280, Brest, France \\ ${ }^{2}$ LOCEAN/IPSL, CNRS/UPMC/IRD/MNHN, Paris, France \\ 3 LEGOS, Université de Toulouse, CNES, CNRS, IRD, UPS, Toulouse, France \\ ${ }^{4}$ GeoStat team, INRIA Bordeaux Sud-Ouest, Talence, France \\ *Corresponding author : Ozge Yelekçi, email address : ozge.yelekci@ifremer.fr
}

\begin{abstract}
:
The frontal activity in coastal regions remains a research field where a large number of open questions needs to be addressed to quantify the potential impact of these processes on dependent systems (e.g. biogeochemical activity). Spatial and seasonal distributions of Sea Surface Temperature (SST) fronts $(\sim 1-100 \mathrm{~km})$ in the vicinity of main French rivers, Gironde and Loire, are explored over the continental shelf North of $45^{\circ} \mathrm{N}$ in the Bay of Biscay. A high resolution (1 km spatial and daily temporal resolutions) dataset of 11 years' (2003 to 2013) remotely sensed SST by MODIS sensor onboard Aqua and Terra satellites has been investigated and compared with coastal numerical model experiments. The detection and characterization fronts with fluctuating amplitudes is achieved through the Singularity Analysis (i.e. the process of calculating the degree of regularity or irregularity of a function at each point in a domain). Seasonality of frontal activity in the Bay of Biscay is then described based on the long-term satellite SST archive and coastal operational model simulations. The identified hot spots of higher frontal occurrences correspond on one hand to previously observed features (e.g. tidal fronts) but also reveal new features. These are investigated to identify fine-scale dynamical drivers. In winter, density fronts are prominent in a coastal strip where freshwater influence is important. In spring, this strip diminishes as plumes detach from the coast, while tidal fronts become apparent in other regions. In summer, tidal fronts in Ushant region and internal wave activity along the shelf break dominate. In autumn, coastal density fronts due to freshwater inputs reappear as these inputs increase, and reduced stratification causes a weakening of the Ushant and shelf break fronts. Additional information and an effort to dynamically interpret these fronts, based on a systematic investigation of the whole seasonal cycle and including modeling insights from coastal operational oceanography, complement the description of frontal activity in the Bay of Biscay.
\end{abstract}




\section{Highlights}

- Seasonality of frontal activity over the Bay of Biscay shelf, in a statistically significant sense, has been documented. Previous studies, which mostly report in situ observations, have a limited temporal continuity, whereas our $1 \mathrm{~km}$ resolution satellite dataset not only covers an 11 year period with a daily temporal resolution but also gives us a synoptic view spatially. The method of front detection in this study is a novel approach that may have so many potential applications in turbulent systems like the oceans. This method has been shown to serve as a valuable tool in image processing and in our study we show that it is an efficient measure of front detection compared with the classical gradient based methods and it can be used not only to detect but quantify the frontal activity both temporally and spatially.

Keywords: Bay of Biscay, Fronts, Submesoscale, Satellite, Sea surface temperature, Singularity exponent 


\section{Introduction}

Since oceans are observed from space, the two-dimensional depiction of the ocean surface circulation is becoming more detailed but also more complex. One of the key dynamical features is fronts (D'Asaro et al., 2011; Ferrari, 2011).

5 These regions, where horizontal gradients of physical or biogeochemical properties are locally increased, play major roles in the exchanges (e.g. heat, gases) between the subsurface and the atmosphere. In particular, they tend to separate flow regions with distinct water masses, albeit with some exchanges across, e.g. due to even finer scale processes. These transition zones have typical acrossscales, termed submesoscale, in the range from infrakilometric to $\sim 10 \mathrm{~km}$.

Several past studies explored the role of fronts in terms of the generated vertical velocities (Taylor \& Ferrari, 2010, e.g.). The effect of submesoscale velocities on biological production is a subject of great interest (Owen, 1981; McGillicuddy et al., 1998; Oschlies \& Garçon, 1998; Lévy et al., 2001; McGillicuddy et al., 2007 , e.g.). Due to this potential importance of frontal structures, together with the possibility to observe them via remote sensing, fronts have been widely mapped globally and also in many shelf regions. Submesoscale effects are be- 
lieved to be very important as shown in the first global remote sensing survey of fronts in Large Marine Ecosystems (Belkin et al., 2009). Many studies have been dedicated to the description of the frontal dynamics of coastal regions, such as in European shelf seas (Simpson \& Hunter, 1974; Simpson et al., 1978; Bowers \& Simpson, 1987; Simpson et al., 1981), over the US Southeastern Continental Shelf (Oey, 1986), along the Northeast US coast (Ullman \& Cornillon, 1999), around South America (Acha et al., 2004), off North-West Iberia (Otero et al., 2009), east China (Hickox et al., 2000; Huang et al., 2010), and in Canadian coastal waters (Cyr \& Larouche, 2014). In light of these previous observations, the main determinants of fronts in coastal seas are known to be combinations of tides, bathymetry, river runoffs, and wind.

The present study aims at improving the characterization and description of frontal activity in the Bay of Biscay, using a recent image processing approach dedicated to turbulent systems. Analyses are focused on the seasonal evolution of frontal activity. Some frontal features in the Bay of Biscay have previously been considered most often in relation with plankton dynamics as in the Ushant front (Schultes et al., 2013), across the continental slope (Fernández et al., 1993), and over the Aquitaine shelf (Albaina \& Irigoien, 2004). However, the different turbulence regimes in the Bay of Biscay shelf remain under-documented except for the tidally driven fronts described mainly in the Irish and Celtic Seas (Simpson \& Hunter, 1974; Simpson et al., 1978, 1981). The Bay of Biscay is arguably an interesting natural laboratory to investigate submesoscale frontal dynamics, where many different processes take place that contribute to the maintenance of frontal activity. Baroclinic tides generated and dissipated over the continental slope and shelf break are responsible for intense mixing that produces large density contrasts. Stirring of these contrasts due to internal tide breaking frequently leads to submesoscale fronts. Spatial variations of frictional 45 forces acting on the barotropic tide can modulate this activity spatially and temporally. This is, for instance, a source of submesoscale in the Ushant front region and other parts of the mid-shelf. River plumes are responsible for major buoyancy contrasts with freshwater input, in particular from Loire and Gironde, 
but their impact on submesoscale activity is not known.

The main objective of this study is to describe the frontal activity over the Bay of Biscay shelf exploring the potential of the Singularity Exponent Analysis to characterize turbulent systems. To this end, we use remotely sensed Sea Surface Temperature (SST) images for the 11 year long period from 2003 to 2013. Furthermore, their analysis is complemented with coastal model experiments to improve the description and the dynamical understanding of observed features. These datasets, which have high spatial resolution $(\sim 1 \mathrm{~km}$ for observation and $2.5 \mathrm{~km}$ for model), allow us to describe the spatial and temporal evolution of frontal activity at the relevant meso- and submesoscales scales.

After describing the data and methods used to analyze frontal occurrence 60 (Section 2), the variability of the SST is briefly described as the background physical setting and the spatial and the temporal variability of frontal activity over 11 years from observations (Section 3), and over 8 years from model experiments (Section 4). Finally, a discussion on the processes explaining these features is presented (Section 5).

\section{Data and methods}

\subsection{Remotely sensed Sea Surface Temperature}

A dataset of nighttime SST (short-wave at $4 \mu \mathrm{m}$ ) remotely sensed by MODIS (Moderate Resolution Imaging Spectroradiometer) onboard Aqua and Terra satellites has been investigated. Level 2 ungridded SST products are downloaded from the PO.DAAC (Physical Oceanography Distributed Active Archive Center) data service provided by NASA. This dataset has $\sim 1 \mathrm{~km}$ spatial resolution. Daily products are considered. The time period extends over 11 years from 2003 to 2013 . The area enclosed by latitudes $45^{\circ} \mathrm{N}$ to $49^{\circ} \mathrm{N}$ and longitudes $0^{\circ} \mathrm{W}$ to $7^{\circ} \mathrm{W}$ is defined as the study region. Cloud contaminated pixels on the

75 images are masked using the flags provided with the Level 2 products. Images that are more than $90 \%$ cloud covered, which constitute $\sim 30 \%$ of the dataset for our region, are discarded from the analyses. The final database is rich of 
3124 images. This number is considered adequate to extract the seasonal and spatial information presented.

\subsection{Numerical Experiments}

\subsubsection{Model configuration}

The numerical experiments considered are part of the coastal operational oceanography project PREVIMER (Dumas et al. (2014), http://www.previmer.org). The model outputs considered are based on the MARS3D (Model for Applications at Regional Scale, Lazure \& Dumas (2008); Duhaut et al. (2008)) primitive equation model in a regional configuration extending from $18^{\circ} \mathrm{W}$ to $9.5^{\circ} \mathrm{E}$ and from $41^{\circ} \mathrm{N}$ to $55^{\circ} \mathrm{N}$ with $40 \sigma$ vertical levels (similar to the configuration described in (Berger et al., 2014)). The spatial resolution is $2.5 \mathrm{~km}$. The tracer advection uses the upwind $5^{\text {th }}$ order and multidimensional MACHO3D scheme (Leonard et al., 1996). Momentum advection uses the $3^{\text {rd }}$ order QUICK. Vertical advection uses a $5^{\text {th }}$ order COMPACT scheme and vertical turbulence is based on a Generalized Length Scale formulation of the $k-\epsilon$ scheme (Umlauf \& Burchard, 2005). Thus, diffusion arises from truncation errors of the advection operators for tracers and momentum. Despite our high order advection schemes we do not expect to resolve submesoscale flow features with scales finer than 7-10 $\Delta \mathrm{x}$, which is $\sim 20 \mathrm{~km}$ (Soufflet et al., 2016).

Open boundary conditions originate from PSY2V4 Mercator-Ocean simulations (http://www.mercator-ocean.fr) with a $1 / 12^{\circ}$ spatial resolution and are located from the area investigated. These fields are provided with a daily temporal resolution. Boundary conditions used for tides are the FES 2004 harmonical components (Lyard et al., 2006). Atmospheric forcings are from Météo-France ARPEGE High Resolution (Déqué et al. 1994; 0.1 spatial resolution and hourly fields) and AROME (Seity et al. 2011; $0.025^{\circ}$ spatial resolution and hourly fields) models. The AROME model with a limited geographical extent is used for a limited domain close to the coast and merged with ARPEGE fields for open ocean.

Modeled outputs are three-days' averages to remove tidal frequencies using 
a Demerliac filter (Demerliac, 1973), and are available from 2006 in real time as an operational forecast (http://www.previmer.org). modeled vertical structure. In Figure 3, the distribution of the misfit between 
modeled and observed temperature and salinity shows a larger spread in the intermediate layers (20-40 $\mathrm{m}$ depth). This feature results from the fact that small errors in the position/sharpness of the thermocline and halocline produce large but localized errors in terms of temperature and salinity. However, most of the differences ranges below $2{ }^{\circ} \mathrm{C}$ in temperature and $1 \mathrm{psu}$ in salinity. In the surface and bottom layers, very few points have a misfit exceeding $2{ }^{\circ} \mathrm{C}$ and $1 \mathrm{psu}$. The distributions also highlight a warm (around $0.9^{\circ} \mathrm{C}$ in surface layers and around $0.38^{\circ} \mathrm{C}$ in deeper layers) and salty (around $0.35-0.37 \mathrm{psu}$ ) bias over the water column. These comparisons with in situ profiles provide a more detailed analysis of model performance and confirm the coherence of the modeled vertical structure.

\subsection{Singularity Exponents}

The frontal structures observed in satellite images are regions delimited by sharp variations of the gradients norms. The detection of these sharp variations can be done according to different methods in image processing.

The present study is based on the use of singularity exponents. Singularity exponent analysis is the process of calculating a measure of the degree of regularity or irregularity of a function at each point in a domain (Turiel et al., 2008). The notion of localized singularity exponent is a generalization, in a microcanonical setting, of the classical multifractal formalism as exposed in Arneodo et al. (1998). Singularity Exponents (SE) are dimensionless quantities evaluated at each point signal (here the SST on the Bay of Biscay represents this signal). The theory behind this indicator is explained in detail in Turiel et al. (2008), where they improved the approach to reach a finer spatial resolution.

Following the main lines from Maji et al. (2013), a signal $s$ is multiscale in a microcanonical sense, if a functional $\left(T_{r} s(x)\right)$, representing a local dissipation of energy in a ball of radius $r$ and centered on $x$, is assumed to be satisfying the equation:

$$
T_{r} s(x)=\alpha(x) r^{h(x)}+o\left(r^{h(x)}\right)(r \rightarrow 0)
$$


where $\alpha(x)$ is an amplitude coefficient and $h(x)$ is the exponent called a singularity exponent or local predictability exponent of the point $x$. This local dissipation of energy $\left(T_{r} s(x)\right)$ is expressed as the gradient's norms of the signal integrated on a ball of radius $r$ centered on $x$ (Yahia et al., 2010; Sudre et al., 2015).

The algorithm to compute the singularity exponents $h(x)$ (Turiel et al., 2006; Pont et al., 2011), solves the equation:

$$
h(x)=\frac{\log \left(\tau_{\psi} s\left(x, r_{0}\right)\right) /\left\langle\tau_{\psi} s\left(., r_{0}\right)\right\rangle}{\log \left(r_{0}\right)}+o\left(\frac{1}{\log \left(r_{0}\right)}\right)
$$

where $\tau_{\psi} s\left(x, r_{0}\right)$ is a wavelet decomposition of the signal $s(x),\left\langle\tau_{\psi} s\left(., r_{0}\right)\right\rangle$ is the average of the wavelet projection over the whole signal, $o\left(\frac{1}{\log \left(r_{0}\right)}\right)$ is a diminishing quantity, and $r_{0}$ is the minimum scale. If the signal $s$ is an image of size $M \times N$, then we choose $r_{0}=1 / \sqrt{M \times N}$.

Following previous studies, this image processing method given by the notion of singularity exponents for edge detection is the most adapted and efficient in the case of natural and turbulent complex signals (Yahia et al., 2010; Kumar Maji \& Yahia, 2014; Turiel et al., 2008; Sudre et al., 2015), compared with other classical approaches in image processing (Maji et al., 2013).

Images have been processed using the software developed by H. Yahia (Yahia et al., 2010). The resulting fields are normalized by the image size such that the parameter SE varies between -0.6 and 2. Figure 4 shows an example of a SST image and singularity exponent analysis applied to that image. Negative values of SE indicate sharp variations of the gradient at all scales, i.e. stronger frontal activity, while positive values denote continuous signals i.e. weak frontal activity (Turiel et al., 2008). The major advantage of using SE instead of calculating the gradient of a signal is that it conveys the information of the scale of the signal's irregularity SE allow us to have an nondimensional classification of all fronts in a set of images, with appropriate multiscale characteristics of each front.

Front detection is performed based on the distribution of the SE. It is considered that a front is located where the largest irregularity in the SST field 
occurs, i.e. where the $\mathrm{SE}$ is the lowest. $\mathrm{SE}$ fields are analyzed in a pixel by estuaries, average SST is $\leq 10{ }^{\circ} \mathrm{C}$ representing the coldest regions in the studied area. In spring is the transition period. The north - south temperature difference

pixel approach. A pixel is considered frontal, if $-0.2 \geq S E \geq-0.6$ for that pixel (Figure 4b). In Figure 4c, it is seen how the SE correlates to the gradient of the SST and the pixels that fall into the frontal pixel range. With a gradient based detection method lower gradient pixels would not have been selected, whereas with the singularity exponent analysis we can detect fronts based on the irregularity of the SST around a pixel, irrespective of the local absolute gradient value there.

Great care was taken to prevent false positive detection of fronts at the edges of the SST maps, at the ocean-land transition or at the boundaries of individual cloud masks (note that issues at the latter would be less problematic because clouds are not stationary so incorrect treatment may not significantly alter the spatial patterns of frontal statistics). To this end, land and cloud masks were extended by 3 pixels (see zoom in Figure $4 \mathrm{~b}$ ). This restriction gives us confidence in the reality of the nearshore frontal patterns observed in Figure 6.

\section{Observed Frontal Activity}

\subsection{Variability of Sea Surface Temperature}

The seasonal distributions of Sea Surface Temperature (SST) are presented to give an overview of the background physical environment of our study area and the natural variability observed in the satellite SST dataset. Figure 5 shows the SST over the Bay of Biscay from 2003 to 2013, averaged over each season. During all seasons, over the offshore oceanic part a large scale north - south temperature gradient exists with warmer waters in the south.

Over the shelf, a more complex seasonal cycle is observed. In winter, a marked temperature gradient (up to $0.5^{\circ} \mathrm{C} \mathrm{km}^{-1}$ amplitude) primarily oriented in the cross-shore direction with a minimal along-shore component is observed over the shelf. Inshore of the $100 \mathrm{~m}$ isobath, north of the Loire and Gironde 
continuously increases and the SST gradient orientation over the shelf becomes partly along-shelf direction. Close to the coast, average SST increases to 15 - 18 ${ }_{225}{ }^{\circ} \mathrm{C}$. Signature of the tidal mixing is observed at the Ushant region with colder waters with average temperatures less than $12{ }^{\circ} \mathrm{C}$ the front and the coast. A similar, but weaker signal of the internal tidal mixing also forms along the shelf break around the $200 \mathrm{~m}$ isobath. In summer, the SST gradient is mainly in the along-shore direction over the shelf with a warm pool in the south-eastern part of the Bay of Biscay with average temperature exceeding $20^{\circ} \mathrm{C}$. During this season, a strong signal induced by tidal mixing is also observed in the Ushant region off Brittany with average SST $\leq 16{ }^{\circ} \mathrm{C}$ on the cold side of the front. Similar cold waters are also observed along the coast south of Brittany. Local minima in temperature are also observed near the shelf break. Note, at 235 the shelf break, the trough-like pattern visible in SST isocontours between $46^{\circ} \mathrm{N}$ and $47^{\circ} \mathrm{N}$ whose amplitude progressively reduces southward. Autumn is again a transition season. The SST gradient orientation reverses back to the cross-shore direction, especially in the vicinity of major estuaries. Surface cooling begins in this season, decreasing the average SST to $12-14{ }^{\circ} \mathrm{C}$ inshore of the $30 \mathrm{~m}$ isobath. Stratification reduction weakens the tidal mixing signal observed in summer. South of $47^{\circ} \mathrm{N}$ approximately between the 50 and $150 \mathrm{~m}$ isobaths, the warmer waters with temperature $\sim 15-16{ }^{\circ} \mathrm{C}$ appear to be intruding towards the north.

Based on these general identified features, the investigations are focused on the frontal activity that accompanies these observed mean field patterns.

\subsection{Spatio-temporal variability of frontal activity}

The spatial distribution of frontal activity is investigated in terms of the occurrence frequency of fronts during each season. The front occurrence frequency on a pixel is defined as the percentage of the times the pixel is a frontal pixel (based on the singularity exponent analysis, see Section 2) out of all times that pixel is cloud-free.

In winter (Figure 6a), the majority of the fronts occur in an along-shore band 
inshore of the $100 \mathrm{~m}$ isobath, with the occurrence frequency ranging between $20 \%$ and $45 \%$. Within this band, the frequency of front occurrence is locally

of $50 \mathrm{~m}$ depth a second patch of fronts is observed with the occurrence frequency between $20 \%$ and $30 \%$. Along the coast, the hot-spots of front occurrences are to the south of the Vilaine, Loire, and Gironde rivers near $47.3^{\circ} \mathrm{N}, 46.8^{\circ} \mathrm{N}$, and 
$45.5^{\circ} \mathrm{N}$, respectively, with frequencies $30 \%$ to $45 \%$. Significant front occurrences

$\mathrm{m}$ isobath. Figure 7 shows the climatology of front occurrence frequency. It is calculated for each month (similarly to the seasonal distributions) and averaged over each box. 
In L (Loire river plume) region, two peaks are observed in April-May and in November-December. The frontal activity is decreasing smoothly after each peak until minima (below 20\%) of frontal activity. Conversely, increases toward maximum values are more abrupt and take place over periods of $\sim 1$ month. In $\mathrm{U}$ (Ushant front) region, the frontal activity is minimum in winter and increases in May. This rate of frontal activity $(\sim 25 \%)$ is sustained during the whole stratified season from May until November. In S (shelf break) region, the frontal activity is very low $(<15 \%)$ in winter. With the onset of seasonal stratification, the frontal activity is increasing to reach high values in May.

\section{Modeled Frontal Activity}

\subsection{Spatio-temporal variability of frontal activity}

To connect the model simulations with the remotely sensed observation analysis performed in this study, the front occurrences have also been estimated from the modeled fields following the same methodology. However, two differences have to be mentioned: i) in the model analysis, there is no cloud coverage so there is no gap in the time series or masked pixels, and ii) modeled SST fileds have a lower resolution of $2.5 \mathrm{~km}$. As displayed in Figure 8, from the continuous simulation from 2006 to 2013, the seasonal front occurrence frequency maps exhibit a good qualitative agreement with the seasonal maps from satellite observations (Figure 6). The wintertime fronts over the inner shelf are followed by the tidal and shelf break fronts in summer, and between them the transition periods in spring and autumn. Intensity of the model front occurrence frequency is generally lower than the observations outside of the frontal regions. The model has difficulties reproducing low but non-zero levels of occurrence, i.e. it has insufficient background frontal activity. Horizontal resolution is $2.5 \mathrm{~km}$, which in 340 practice means that features smaller than $\sim 10 \mathrm{~km}$ scale cannot be represented by the model, whereas satellite observations can in practice detect arbitrary contrasts between one pixel and its neighbors. Nonresolved ocean dynamics and atmospheric variability (e.g. fine-scale random fluctuations of winds and heat 
fluxes), possibly in combination, are the presumable source of this difference. frontal occurrence. Both $\mathrm{U}$ and $\mathrm{S}$ regions remain active during the stratified period with values around or exceeding $30 \%$ from June until October-November. A time shift is also observed in the peak in the beginning of spring. This peak 
375 is visible in April-May in remotely sensed observations when the model peaks towards May-June.

The use of coastal modeling in this analysis allows us to explore the full seasonal cycle of the frontal activity and its interannual variability. In Figure 10, singularity exponents describe a seasonal cycle with a changing amplitude following the different year (negative values of the singularity exponents represent frontal activity). Although, generally coherent with the climatology, we can notice a marked interannual variability. In the Loire region (Figure 10a), most intense frontal activity are the winters of 2006-2007 and 2011-2012 and the summer 2010. The Ushant front (Figure 10b) displays a more stable seasonal cycle with small singularity exponents from summer to the beginning of autumn. In the shelf break region (Figure 10c), the seasonal cycle tends to have an increasing amplitude with time. From 2006 to 2009, values of singularity exponents remain in a limited range (from $\sim-0.2-\sim 0.4$ ). More recently, from 2010 and onward, maximum values exceed 0.6 representing period with less intense fronts in winter compared with previous years.

\section{Discussion}

Based on these observations and numerical experiments, the frontal activity in the Bay of Biscay has been described including the spatial and temporal structures of the front distribution. The processes driving this frontal activity are discussed following a classification related to the nature of the front: freshwater fronts, tidal fronts, and shelf break fronts. This classification is possible thanks to the Singularity Exponent Analysis approach, which, by construction, can capture different turbulent regimes in the ocean.

\subsection{Freshwater fronts}

$400 \quad$ Starting from mid-autumn until mid-spring, the plumes of the Gironde and Loire follow the coast line to the north (Puillat et al., 2004). The inner shelf North of these estuaries (i.e. up to the location of the $30-100 \mathrm{~m}$ isobath, on average $20-40 \mathrm{~km}$ from the coast) is mainly occupied by relatively fresher waters 
with salinity $\leq 30$. During these seasons, prevailing South-West (downwelling favorable) winds and increased freshwater input help maintain a low salinity band attached to the coast (Puillat et al., 2004; Lazure et al., 2006). The limit of this region of freshwater influence corresponds to large frontal activity (Figures 6 and 8). For example, in Figure 11c,d, the vertical structure of a density front from model simulations is shown for a winter condition (11 February 2008).

In this season, closer to the coast plumes are surface-advected (Yankovsky \& Chapman, 1997). They occupy the upper $\sim 10 \mathrm{~m}$ layer and cause a haline stratification. As explained in Ullman \& Cornillon (2001), when the shelf is subject to winter cooling, this upper fresher/lighter layer cools faster than the offshore well-mixed waters, because the convection due to heat losses is frequently arrested by the halocline. Towards the midshelf, they are bottom-trapped as explained in Chapman \& Lentz (1994). The waters with temperature $\leq 10^{\circ} \mathrm{C}$ are then confined along the coast (Figure 5a). Due to this differential cooling, we can identify these SST fronts as freshwater fronts. They occur mainly at the offshore edge of this freshwater band, where average cross-front temperature difference reaches $2{ }^{\circ} \mathrm{C} \mathrm{km}^{-1}$. Note that, in the example MODIS image in Figure 11a, interesting signs of classical submesoscale baroclinic instability can be seen with filamentary and eddy features folding this plume edge front between the waters with relatively uniform $\mathrm{SST} \geq 11.2^{\circ} \mathrm{C}$ and colder inshore waters. The signature of dynamical instability becomes less clear fronts south, perhaps because stirring of the flow by topographic constraints is stronger (for example, in the vicinity of the Plateau de Rochebonne).

The seasonal behavior of the freshwater fronts are detailed in Figure 10a from the singularity exponent averaged over the localized region in the vicinity of the Loire river plume (Figure 1b). Based on the continuous dataset from modeled fields, the seasonal variability is confirmed. Indeed, it is seen that the seasonal signal of the frontal activity correlates to the river discharge into this region (not shown). A sharp increase in frontal activity coincides with the first increase in river fluxes each year around the beginning of autumn. In autumn, the band of fresh water fronts are more coherent and pronounced compared 
to winter such that they reach a frequency of $50 \%$ of the time. However, it should be noted that in this season the frontal occurrence frequency is observed to be noisier in all regions of the bay. Cloud cover is highest in autumn (not shown). This reduces the number of cloud free images/pixels, but also increases the number of cloud contaminated pixels that are not properly detected by the masking algorithm of the MODIS dataset, hence the noisier SST signal at this season. The pronounced coastal strip of increased frontal activity in autumn can be explained by the average poleward current over the shelf in this season that carries warmer waters to the north (Lazure et al., 2008; Le Cann \& Serpette, 2009). The coastal waters starting to cool in autumn are surrounded by these warmer waters, and furthermore, are confined by the alongshore current creating a sharper temperature gradient (Figure 12). Figure 9a shows the interanuual variability of front occurrence in Loire region. The winters with increased frontal strength is found to be occurring after dry summers (not shown). This can be explained by the fact that dry summers cause warmer coastal waters that create larger gradients when the river discharge starts to reappear in autumn. In this season, fronts are visible consistently along the $30 \mathrm{~m}$ isobath in model (Figure 8d) and in observations (Figure 6d). From autumn to winter as the plume develops, the maximum frontal occurrence travels offshore from the vicinity of the $30 \mathrm{~m}$ to a band between the 50 to $100 \mathrm{~m}$ isobaths 455 (Figure 8a and Figure 6a). Around January, the frontal activity peaks and then declines towards the spring. The minimum activity is observed during March to April because the main frontal activity associated with the edge of the plume is located offshore of the L region. In spring, fronts appear just adjacent to the coast (Figure 6b), unlike in winter when they occur as far as the $100 \mathrm{~m}$ isobath. River run-offs decrease during spring (Puillat et al., 2004) and the prevailing winds reverse to northwestern (upwelling favorable) direction. This prevents the along shore northward propagation of the plumes and cause them to detach from the coast and disperse (Lazure \& Jégou, 1998; Puillat et al., 2006, 2004). Freshwater no longer occupies such an extensive coastal area, and the above mentioned low salinity structure remains inside the river mouths. During 
summer, when the river discharge is minimum, there is an increase in frontal activity along the coast which can be attributed to the tidal fronts.

The process explaining the development of similar density fronts has been described in Chapman \& Lentz (1994) and Yankovsky \& Chapman (1997). In the Bay of Biscay, these fronts remain difficult to observe (in in situ or remotely) because their typical spatial scales are close to $1 \mathrm{~km}$. As for the realistic simulations, like ours, still tend to be a little too coarse to fully resolve the processes at play. Nevertheless, the present results illustrate, from ocean observations and coastal model simulations, the development of these fronts initiated by a surface-to-bottom density gradient over a sloping continental shelf as well as the "trapped" fronts (Chapman \& Lentz, 1994), here along the $100 \mathrm{~m}$ isobath.

\subsection{Tidal fronts}

Tidal mixing at the coast that results from the interaction between the tidal currents and the bottom topography can create a cool vertically mixed water mass. A tidal front is the region of temperature contrast separating this mixed water from the thermally stratified offshore waters. The northeastern European continental shelf is a well studied region in terms of the dynamics of such tidal fronts (Simpson \& Hunter, 1974; Simpson et al., 1978; Pingree \& Griffiths, 1978; Bowers \& Simpson, 1987). In the investigated region tidal fronts are observed in the Iroise Sea and along the coasts of Pointe de Penmarc'h, Archipel des Glénans, Belle-île, and Ile d'Yeu. Their appearance coincides with the onset of surface warming and stratification increase in spring. They become more prominent through summer and early autumn as the stratification is established. Then, they disappear in winter. The most significant tidal front occurrence among these is the Ushant front, which is the most prominent feature observed in SST as in Figure 13a. Its location is observed from the satellite dataset to be within a 5 - $10 \mathrm{~km}$ wide patch along the $\sim 100 \mathrm{~m}$ isobath off west of Brittany, which is in accordance with previous studies (Mariette \& Le Cann, 1985; Le Boyer et al., 2009; Pasquet et al., 2012; Chevallier et al., 2014, e.g.). This patch of frontal occurrences gradually expands to a much larger area from summer 
to autumn and appears less structured. Pasquet et al. (2012) explains the expansion and the deviation from the predicted front location as the dispersion of the mixed waters for which baroclinic instability is mostly responsible (the prediction is based on the criterion that compares the relative importance of mixing effects (proportional to $u^{3}$ ) and resistance to mixing (assumed to vary as $h$, the depth of the water column), Simpson \& Hunter, 1974). We also observed that a second band of fronts appears inshore of the main frontal region near the $50 \mathrm{~m}$ isobath as previously observed (Pasquet et al., 2012, e.g).

Figure 10b shows the seasonality of the frontal activity in the Ushant region. As expected in a tidally dominated coastal area, the frontal activity increases in spring, with the onset of the seasonal stratification, and peaks in July - August. From autumn to spring the frontal activity is significantly decreased, with some small but sharp increases around February, which is possibly caused by storms or extreme atmospheric events occurring in the Iroise Sea region.

\subsection{Shelf break front}

Celtic and Armorican shelf breaks have been studied as one of the major large amplitude internal tidal wave generation sites in the world (Baines, 1982; Pingree et al., 1984; Serpette \& Mazé, 1989; Pichon \& Mazé, 1990), with La chapelle bank in the Bay of Biscay identified as a major generation region (Pairaud et al., 2010; New \& Pingree, 1990; Pichon \& Correard, 2006). In the Bay of Biscay, shelf break cooling and enhanced biological activity in its vicinity were first associated with internal tidal waves by Pingree et al. (1981). They lift cooler water (and nutrients) to the surface especially at spring tides during summer months (New, 1988; New \& Pingree, 1990; Pingree \& New, 1995). Large internal tidal waves are generated due to the interaction between the barotropic tidal currents and steep topography at the shelf break in the presence of strong stratification and they travel both onshelf and offshelf along the seasonal thermocline (Pingree \& New, 1995; Pairaud et al., 2010). A large fraction of these waves dissipate locally through breaking which results in mixing. How this energy dissipation and mixing is distributed as a function of depth has important consequences 
for tracer fluxes and critically depends on the background stratification. When a sharp thermocline is present, as during summer in the Bay of Biscay, a significant fraction of the mixing involves thermocline and surface waters. Figure $14 \mathrm{c}$ shows the vertical structure of such a front. The surface manifestation of this mixing is described by Pingree \& New (1995) as a 1 to $2{ }^{\circ} \mathrm{C}$ cooler than further on the shelf, $\sim 30 \mathrm{~km}$ wide patch along the shelf break from late spring to autumn. Figure 14a is one such example from 20/10/2007, where the region above the shelf break north of $46.5^{\circ} \mathrm{N}$ is $\sim 1{ }^{\circ} \mathrm{C}$ colder. In our study, frontal activity is observed to be very significant in thermally stratified months along the $200 \mathrm{~m}$ isobath. It first appears in spring and prevails through summer. In autumn, the number of frontal pixels in this region increases and the patch of occurrence extends spatially. In Figure 9, this is seen in model simulations as a peak in frontal activity at the shelf break region in October. Pingree et al. (1981) report on the broadening of the cool water band in this region towards autumn and explain it as the release of the potential energy stored in summer in the form of irregular baroclinic eddies. Note that in Figure 14a the patch of cold water at the shelf break is elongated and folded in ways that reflect mesoscale stirring with several mushroom-like cold SST patterns, (e.g., near $4.5^{\circ} \mathrm{W}, 46.5^{\circ} \mathrm{N}$ or $\left.5.7^{\circ} \mathrm{W}, 46.7^{\circ} \mathrm{N}\right)$. The extent to which this mesoscale activity 545 results from local instabilities due to internal wave mixing itself (as opposed to being preexistent and related to other processes) is unknown at the present. Our model in its present version cannot be used to explore this, because there is a noticeable model bias at this season in the box S sector. There, the real ocean has its main temperature contrast over the slope whereas it is located over the shelf in the model (albeit just a few tens of kilometers too far north). This is expected to result in a very different expression for the instability processes, if only because the baroclinic Rossby radius is much greater over the slope than over the shelf. As a consequence the model is unable to produce large mesoscale structures, which unavoidably affects frontal statistics.

Figure 10c presents the seasonal cycle of the shelf break frontal activity is presented. The shape of the seasonal signal is correlated to the seasonality of the 
stratification, which is slightly asymmetrical in that it gradually increases from the beginning of spring through summer, but rapidly declines in autumn. The maximum activity occurs towards the end of summer and beginning of autumn, which agrees with the peak we observe in October (in the satellite data in Figure 7 and in model simulations Figure 9).

\section{Conclusion}

The length of the observation period by satellites providing high resolution SST information gives the opportunity to explore the frontal activity and to determine frontal statistics with great reliability. The present study considering 11 years (2003 to 2013) of remotely sensed SST in the Bay of Biscay shelf influenced by the Loire and Gironde river plumes provides an integrated view of the front occurrence, based on the singularity exponent decomposition. The use of singularity analysis allows inferring the multi-scale signature of the fronts. The front detection achieved by this method and the statistical analyses lead to a robust classification. The seasonal fluctuations of the frontal activity, deduced from remotely sensed observations and confirmed in numerical experiments, highlight the variety and complexity of the processes responsible for the front generation. Indeed, in summer and autumn, tidal and shelf break fronts developing in stratified conditions are dominant. Conversely, from late autumn to beginning of spring, frontal activity is concentrated over the continental shelf with localized mid-shelf frontal intensification. These winter and spring density fronts are the product of combined forcings. First, the river flow, which provides important sources of freshwater, determines where density gradients are located. Then, the air-sea heat fluxes will increase the temperature contrast between mid-shelf and coastal waters. These hydrodynamical conditions are favorable to the development of coastal density fronts trapped by the bottom boundary layer (Chapman \& Lentz, 1994).

The temporal climatology of the frontal activity confirms that seasonal modulations of frontal activity responds to sub-regional environmental characteris- 
tics that we strived to identify and describe. Over the continental shelf in the Bay of Biscay, the frontal activity is maximum in winter. On the other hand, in the Iroise Sea or over the shelf break, the peak of the activity is observed in summer. Based on this first description of the spatial and temporal variability of frontal activity, two main regimes (winter vs. summer) have been identified with the development of previously poorly observed density mid-shelf fronts in winter.

These frontal regimes we describe through their SST imprint must have distinct dynamical behaviors. Indeed, they take place in different parts of the shelf, where the role of friction and topographic stirring are different. In addition, their thermohaline structure also differs, which has some important implications in terms of the amplitude and modal structure of the frontal instabilities they can be subjected to (Hetland, 2010, 2016).

Biological implications of these frontal regimes would also need to be studied specifically. At present, we can only say that the seasonal Ushant frontal zone has well-marked contrasts in plankton composition (Schultes et al., 2013). We presume this must also hold for the more inshore freshwater fronts which are robust semi-permanent features in the Bay of Biscay. The role of the ephemeral fronts also captured by our analysis is less clear. General considerations suggest that they may lead to aggregation and dispersion of biological materials (Mahadevan, 2016), particularly the buoyant ones (Capet et al., 2008). Clarifying the submesoscale links between ocean physics, biogeochemistry and ecosystem dynamics is the subject of intense research to which the Bay of Biscay has presumably important elements to offer.

\section{Acknowledgments}

This study is part of the LEFE/GMMC project ENIGME and the COCTO project (SWOT Science Team Program). The funding is provided for the Ph.D. study of Ö. Yelekçi by Brittany region and IFREMER. We would like to thank Daneeja Mawren, Louis Marié, Sébastien Theetten, Frédéric Vandermeirsch, 
Bernard Le Cann, Franck Dumas, Pascal Lazure, and Francis Gohin for insightful discussions; and PREVIMER project for model outputs. We are grateful to Pr. John H. Simpson and to an anonymous referee for constructive comments on this manuscript.

\section{References}

${ }_{620}$ Acha, E. M., Mianzan, H. W., Guerrero, R. A., Favero, M., \& Bava, J. (2004). Marine fronts at the continental shelves of austral South America. Journal of Marine Systems, 44, 83-105.

Albaina, A., \& Irigoien, X. (2004). Relationships between frontal structures and zooplankton communities along a cross-shelf transect in the Bay of Biscay(1995 to 2003). Marine Ecology Progress Series, 284.

Arneodo, A., Audit, B., Bacry, E., Manneville, S., Muzy, J. F., \& Roux, S. G. (1998). Thermodynamics of fractal signals based on wavelet analysis: application to fully developed turbulence data and DNA sequences. Physica A: Statistical Mechanics and its Applications, 254, 24-45.

Baines, P. G. (1982). On internal tide generation models. Deep Sea Research Part A. Oceanographic Research Papers, 29, 307-338.

Belkin, I. M., Cornillon, P. C., \& Sherman, K. (2009). Fronts in Large Marine Ecosystems. Progress in Oceanography, 81, 223-236.

Berger, H., Dumas, F., Petton, S., \& Lazure, P. (2014). Evaluation of the hydrology and dynamics of the operational mars3d configuration of the bay of Biscay. Mercator Ocean Newsletter, 49.

Bowers, D. G., \& Simpson, J. H. (1987). Mean position of tidal fronts in European-shelf seas. Continental Shelf Research, 7, 35-44.

Capet, X., Campos, E. J., \& Paiva, A. M. (2008). Submesoscale activity over the Argentinian shelf. Geophysical Research Letters, 35. 
Chapman, D. C., \& Lentz, S. J. (1994). Trapping of a Coastal Density Front by the Bottom Boundary Layer. Journal of Physical Oceanography, 24, 14641479 .

Chevallier, C., Herbette, S., Marié, L., Le Borgne, P., Marsouin, A., Péré, S., Levier, B., \& Reason, C. (2014). Observations of the Ushant front displacements with MSG/SEVIRI derived sea surface temperature data. Remote Sensing of Environment, 146, 3-10.

Cyr, F., \& Larouche, P. (2014). Thermal Fronts Atlas of Canadian Coastal Waters. Atmosphere-Ocean, 0, 1-25.

D'Asaro, E., Lee, C., Rainville, L., Harcourt, R., \& Thomas, L. (2011). Enhanced Turbulence and Energy Dissipation at Ocean Fronts. Science, 332, $318-322$.

Demerliac, A. (1973). Le niveau moyen de la mer. Calcul du niveau moyen journalien. Rapport du SHOM, .

Déqué, M., Dreveton, C., Braun, A., \& Cariolle, D. (1994). The ARPEGE/IFS atmosphere model: a contribution to the French community climate modelling. Climate Dynamics, 10, 249-266.

Duhaut, T., Honnorat, M., \& Debreu, L. (2008). Développements numériques pour le modèle MARS. PREVIMER report-Ref: 06/2 210, 290. (2014). General Introduction: PREVIMER, a French pre-operational coastal ocean forecasting capability. Mercator Ocean-Quarterly Newsletter, (pp. 3-8).

Fernández, E., Cabal, J., Acuña, J. L., Bode, A., Botas, A., \& García-Soto, C. (1993). Plankton distribution across a slope current-induced front in the southern Bay of Biscay. Journal of Plankton Research, 15, 619-641.

Ferrari, R. (2011). A Frontal Challenge for Climate Models. Science, 332, 316-317. 
Hetland, R. D. (2010). The effects of mixing and spreading on density in nearfield river plumes. Dynamics of Atmospheres and Oceans, 49, 37-53.

Hetland, R. D. (2016). Suppression of baroclinic instabilities in buoyancy driven flow over sloping bathymetry. Journal of Physical Oceanography, .

Hickox, R., Belkin, I., Cornillon, P., \& Shan, Z. (2000). Climatology and seasonal variability of ocean fronts in the East China, Yellow and Bohai seas from satellite SST data. Geophysical Research Letters, 27, 2945-2948.

Huang, D., Zhang, T., \& Zhou, F. (2010). Sea-surface temperature fronts in the Yellow and East China Seas from TRMM microwave imager data. Deep Sea Research Part II: Topical Studies in Oceanography, 57, 1017-1024.

Kumar Maji, S., \& Yahia, H. M. (2014). Edges, transitions and criticality. Pattern Recognition, 47, 2104-2115.

Lamouroux, J., Charria, G., De Mey, P., Raynaud, S., Heyraud, C., Craneguy, P., Dumas, F., \& Le Hénaff, M. (2016). Objective assessment of the contribution of the RECOPESCA network to the monitoring of 3D coastal ocean variables in the Bay of Biscay and the English Channel. Ocean Dynamics, $66,567-588$.

${ }_{685}$ Lazure, P., \& Dumas, F. (2008). An externalinternal mode coupling for a 3D hydrodynamical model for applications at regional scale (MARS). Advances in Water Resources, 31, 233-250.

Lazure, P., Dumas, F., \& Vrignaud, C. (2008). Circulation on the Armorican shelf (Bay of Biscay) in autumn. Journal of Marine Systems, 72, 218-237.

Lazure, P., \& Jégou, A.-M. (1998). 3D modelling of seasonal evolution of Loire and Gironde plumes on Biscay Bay continental shelf. Oceanologica Acta, 21, $165-177$.

Lazure, P., Jégou, A.-M., \& Kerdreux, M. (2006). Analysis of salinity measurements near islands on the French continental shelf of the Bay of Biscay. Scientia Marina, 70, 7-14. 
Le Borgne, P., Roquet, H., \& Merchant, C. J. (2011). Estimation of sea surface temperature from the Spinning Enhanced Visible and Infrared Imager, improved using numerical weather prediction. Remote Sensing of Environment, $115,55-65$.

Le Boyer, A., Cambon, G., Daniault, N., Herbette, S., Le Cann, B., Marié, L., \& Morin, P. (2009). Observations of the Ushant tidal front in September 2007. Continental Shelf Research, 29, 1026-1037.

Le Cann, B., \& Serpette, A. (2009). Intense warm and saline upper ocean inflow in the southern Bay of Biscay in autumnwinter 20062007. Continental Shelf Research, 29, 1014-1025.

Leblond, E., Lazure, P., Laurans, M., Rioual, C., Woerther, P., Quemener, L., \& Berthou, P. (2010). The Recopesca Project : a new example of participative approach to collect fisheries and in situ environmental data. CORIOLIS Quarterly Newsletter, (pp. 40-48).

Leonard, B. P., Lock, A. P., \& MacVean, M. K. (1996). Conservative explicit unrestricted-time-step multidimensional constancy-preserving advection schemes. Monthly Weather Review, 124, 2588-2606.

Lévy, M., Klein, P., \& Treguier, A.-M. (2001). Impact of sub-mesoscale physics on production and subduction of phytoplankton in an oligotrophic regime. Journal of Marine Research, 59, 535-565.

Lyard, F., Lefevre, F., Letellier, T., \& Francis, O. (2006). Modelling the global ocean tides: modern insights from FES2004. Ocean Dynamics, 56, 394-415.

Mahadevan, A. (2016). The Impact of Submesoscale Physics on Primary Productivity of Plankton. Annual Review of Marine Science, 8.

Maji, S. K., Pont, O., Yahia, H., \& Sudre, J. (2013). Inferring Information Across Scales in Acquired Complex Signals. In T. Gilbert, M. Kirkilionis, \& G. Nicolis (Eds.), Proceedings of the European Conference on Complex 
Systems 2012 Springer Proceedings in Complexity (pp. 209-226). Springer International Publishing.

Mariette, V., \& Le Cann, B. (1985). Simulation of the formation of Ushant thermal front. Continental Shelf Research, 4, 637-660.

McGillicuddy, D. J., Anderson, L. A., Bates, N. R., Bibby, T., Buesseler, K. O., Carlson, C. A., Davis, C. S., Ewart, C., Falkowski, P. G., Goldthwait, S. A., Hansell, D. A., Jenkins, W. J., Johnson, R., Kosnyrev, V. K., Ledwell, J. R., Li, Q. P., Siegel, D. A., \& Steinberg, D. K. (2007). Eddy/Wind Interactions Stimulate Extraordinary Mid-Ocean Plankton Blooms. Science, 316, 10211026.

McGillicuddy, D. J., Robinson, A. R., Siegel, D. A., Jannasch, H. W., Johnson, R., Dickey, T. D., McNeil, J., Michaels, A. F., \& Knap, A. H. (1998). Influence of mesoscale eddies on new production in the Sargasso Sea. Nature, 394, 263266.

New, A. L. (1988). Internal tidal mixing in the Bay of Biscay. Deep Sea Research Part A. Oceanographic Research Papers, 35, 691-709.

New, A. L., \& Pingree, R. D. (1990). Evidence for internal tidal mixing near the ${ }_{740}$ shelf break in the Bay of Biscay. Deep Sea Research Part A. Oceanographic Research Papers, 37, 1783-1803.

Oey, L.-Y. (1986). The Formation and Maintenance of Density Fronts on the U.S. Southeastern Continental Shelf during Winter. Journal of Physical Oceanography, 16, 1121-1135.

Oschlies, A., \& Garçon, V. (1998). Eddy-induced enhancement of primary production in a model of the North Atlantic Ocean. Nature, 394, 266-269.

Otero, P., Ruiz-Villarreal, M., \& Peliz, Á. (2009). River plume fronts off NW Iberia from satellite observations and model data. ICES Journal of Marine Science: Journal du Conseil, . 
Owen, R. W. (1981). Fronts and eddies in the sea: mechanisms, interactions and biological effects. Analysis of marine ecosystems, (pp. 197-233).

Pairaud, I. L., Auclair, F., Marsaleix, P., Lyard, F., \& Pichon, A. (2010). Dynamics of the semi-diurnal and quarter-diurnal internal tides in the Bay of Biscay. Part 2: Baroclinic tides. Continental Shelf Research, 30, 253-269.

Pasquet, A., Szekely, T., \& Morel, Y. (2012). Production and dispersion of mixed waters in stratified coastal areas. Continental Shelf Research, 3940, $49-77$.

Pichon, A., \& Correard, S. (2006). Internal tides modelling in the Bay of Biscay. Comparisons with observations. Scientia Marina, 70, 65-88.

Pichon, A., \& Mazé, R. (1990). Internal Tides over a Shelf Break: Analytical Model and Observations. Journal of Physical Oceanography, 20, 657-671.

Pingree, R. D., \& Griffiths, D. K. (1978). Tidal fronts on the shelf seas around the British Isles. Journal of Geophysical Research: Oceans, 83, 4615-4622.

Pingree, R. D., Griffiths, D. K., \& Mardell, G. T. (1984). The Structure of the Internal Tide at the Celtic Sea Shelf Break. Journal of the Marine Biological Association of the United Kingdom, 64, 99-113.

Pingree, R. D., Mardell, G. T., \& Cartwright, D. E. (1981). Slope Turbulence, Internal Waves and Phytoplankton Growth at the Celtic Sea Shelf-Break [and Discussion]. Philosophical Transactions of the Royal Society of London A: Mathematical, Physical and Engineering Sciences, 302, 663-682.

Pingree, R. D., \& New, A. L. (1995). Structure, seasonal development and sunglint spatial coherence of the internal tide on the Celtic and Armorican shelves and in the Bay of Biscay. Deep Sea Research Part I: Oceanographic Research Papers, 42, 245-284.

775 Pont, O., Turiel, A., \& Yahia, H. (2011). An Optimized Algorithm for the Evaluation of Local Singularity Exponents in Digital Signals. In J. K. Aggarwal, 
R. P. Barneva, V. E. Brimkov, K. N. Koroutchev, \& E. R. Korutcheva (Eds.), Combinatorial Image Analysis number 6636 in Lecture Notes in Computer Science (pp. 346-357). Springer Berlin Heidelberg.

Puillat, I., Lazure, P., Jegou, A.-M., Lampert, L., \& Miller, P. (2006). Mesoscale hydrological variability induced by northwesterly wind on the French continental shelf of the Bay of Biscay. Scientia Marina, 70, 15-26.

Puillat, I., Lazure, P., Jégou, A. M., Lampert, L., \& Miller, P. I. (2004). Hydrographical variability on the French continental shelf in the Bay of Biscay, during the 1990s. Continental Shelf Research, 24, 1143-1163.

Schultes, S., Sourisseau, M., Le Masson, E., Lunven, M., \& Marié, L. (2013). Influence of physical forcing on mesozooplankton communities at the Ushant tidal front. Journal of Marine Systems, 109110, S, S191-S202.

Seity, Y., Brousseau, P., Malardel, S., Hello, G., Bénard, P., Bouttier, F., Lac, C., \& Masson, V. (2011). The AROME-France convective-scale operational model. Monthly Weather Review, 139, 976-991.

Serpette, A., \& Mazé, R. (1989). Internal tides in the Bay of Biscay: a twodimensional model. Continental Shelf Research, 9, 795-821.

Simpson, J. H., Allen, C. M., \& Morris, N. C. G. (1978). Fronts on the continental shelf. Journal of Geophysical Research: Oceans, 83, 4607-4614.

Simpson, J. H., Crisp, D. J., \& Hearn, C. (1981). The Shelf-Sea Fronts: Implications of their Existence and Behaviour [and Discussion]. Philosophical Transactions of the Royal Society of London A: Mathematical, Physical and Engineering Sciences, 302, 531-546.

Simpson, J. H., \& Hunter, J. R. (1974). Fronts in the Irish Sea. Nature, 250, 404-406.

Soufflet, Y., Marchesiello, P., Lemarié, F., Jouanno, J., Capet, X., Debreu, L., \& Benshila, R. (2016). On effective resolution in ocean models. Ocean Modelling, 98, 36-50. 
Sudre, J., Yahia, H., Pont, O., \& Garçon, V. (2015). Ocean turbulent dynamics at super resolution from optimal multiresolution analysis and multiplicative cascade. IEEE Transactions on Geoscience and Remote Sensing, 2015, TGRS--2014-00385.R2.

Taylor, J. R., \& Ferrari, R. (2010). Buoyancy and Wind-Driven Convection at Mixed Layer Density Fronts. Journal of Physical Oceanography, 40, 12221242.

Turiel, A., Pérez-Vicente, C. J., \& Grazzini, J. (2006). Numerical methods for the estimation of multifractal singularity spectra on sampled data: a comparative study. Journal of Computational Physics, 216, 362-390.

815 Turiel, A., Solé, J., Nieves, V., Ballabrera-Poy, J., \& García-Ladona, E. (2008a). Tracking oceanic currents by singularity analysis of Microwave Sea Surface Temperature images. Remote Sensing of Environment, 112, 2246-2260.

Turiel, A., Yahia, H., \& Pérez-Vicente, C. J. (2008b). Microcanonical multifractal formalisma geometrical approach to multifractal systems: Part I. Singularity analysis. Journal of Physics A: Mathematical and Theoretical, 41, 15501 .

Ullman, D. S., \& Cornillon, P. C. (1999). Satellite-derived sea surface temperature fronts on the continental shelf off the northeast U.S. coast. Journal of Geophysical Research: Oceans, 104, 23459-23478.

825

Ullman, D. S., \& Cornillon, P. C. (2001). Continental shelf surface thermal fronts in winter off the northeast US coast. Continental Shelf Research, 21, $1139-1156$.

Umlauf, L., \& Burchard, H. (2005). Second-order turbulence closure models for geophysical boundary layers. A review of recent work. Continental Shelf Research, 25, 795-827. 
Yahia, H., Sudre, J., Pottier, C., \& Garçon, V. (2010). Motion analysis in oceanographic satellite images using multiscale methods and the energy cascade. Pattern Recognition, 43, 3591-3604.

Yankovsky, A. E., \& Chapman, D. C. (1997). A simple theory for the fate of buoyant coastal discharges*. Journal of Physical Oceanography, 27, 13861401. 


\section{Figures}

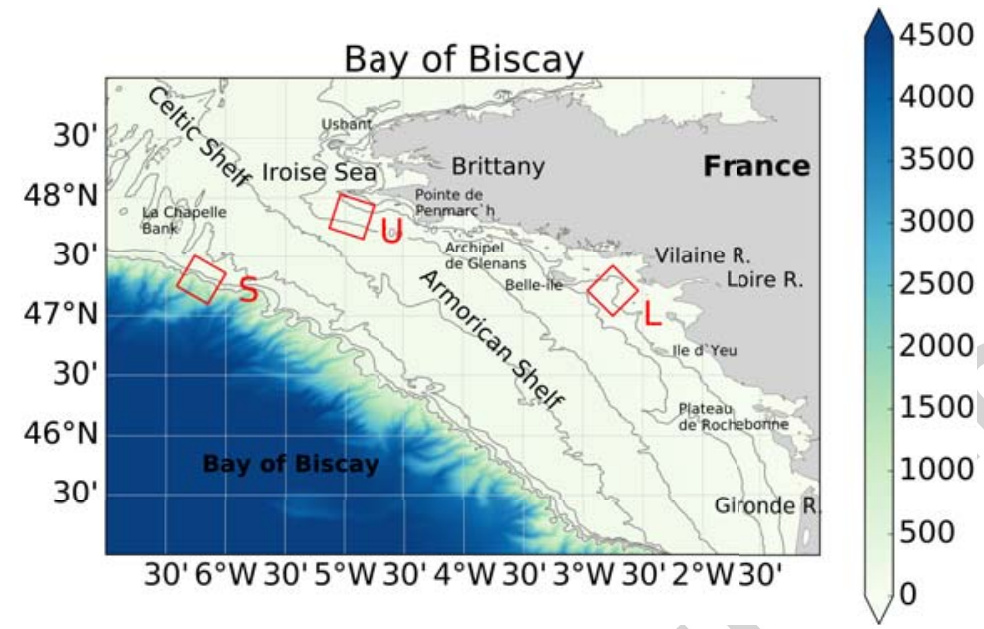

Figure 1: Map of the Bay of Biscay north of $45^{\circ} \mathrm{N}$ with bathymetry $(30,50,100,125,150,200$ and $500 \mathrm{~m}$ isobaths are additionally drawn in gray), showing important geographical features and the locations of the boxes over which time-series analyses are performed (red). 
a) SST bias over the domain $(<E>=\langle$ MODEL $>-<O B S>$ )

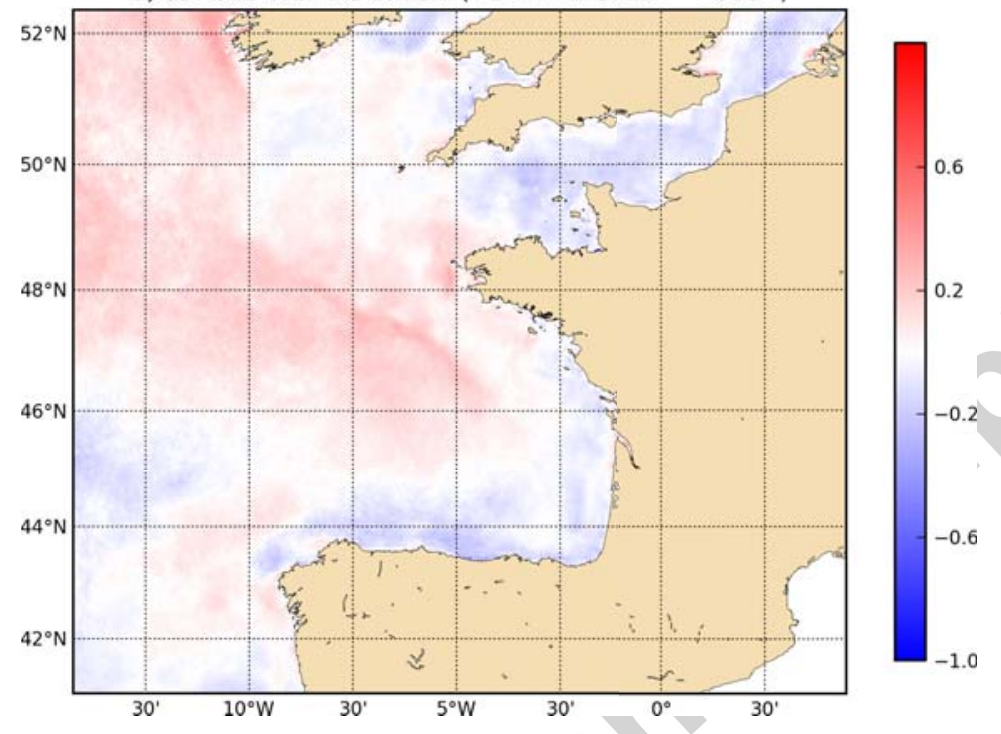

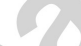

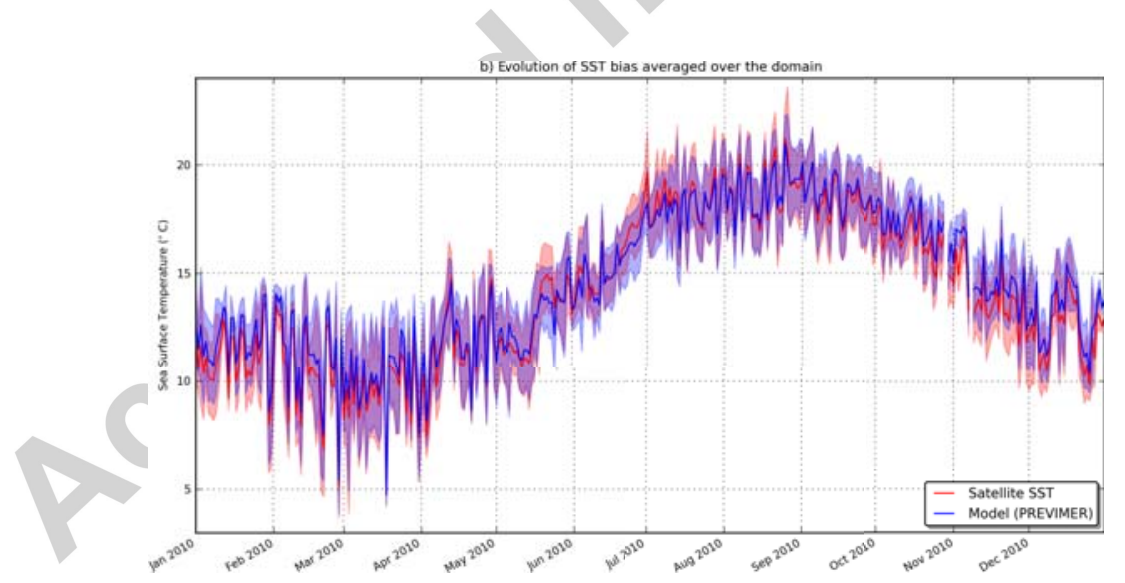

Figure 2: Comparison between observed (SEVIRI satellite SST) and modeled (PREVIMER) sea surface temperature. a) Mean bias between model and observations for the year 2010 . b) Temporal evolution of the SST bias during 2010. The shape of the curves represents the spatial standard deviation. 

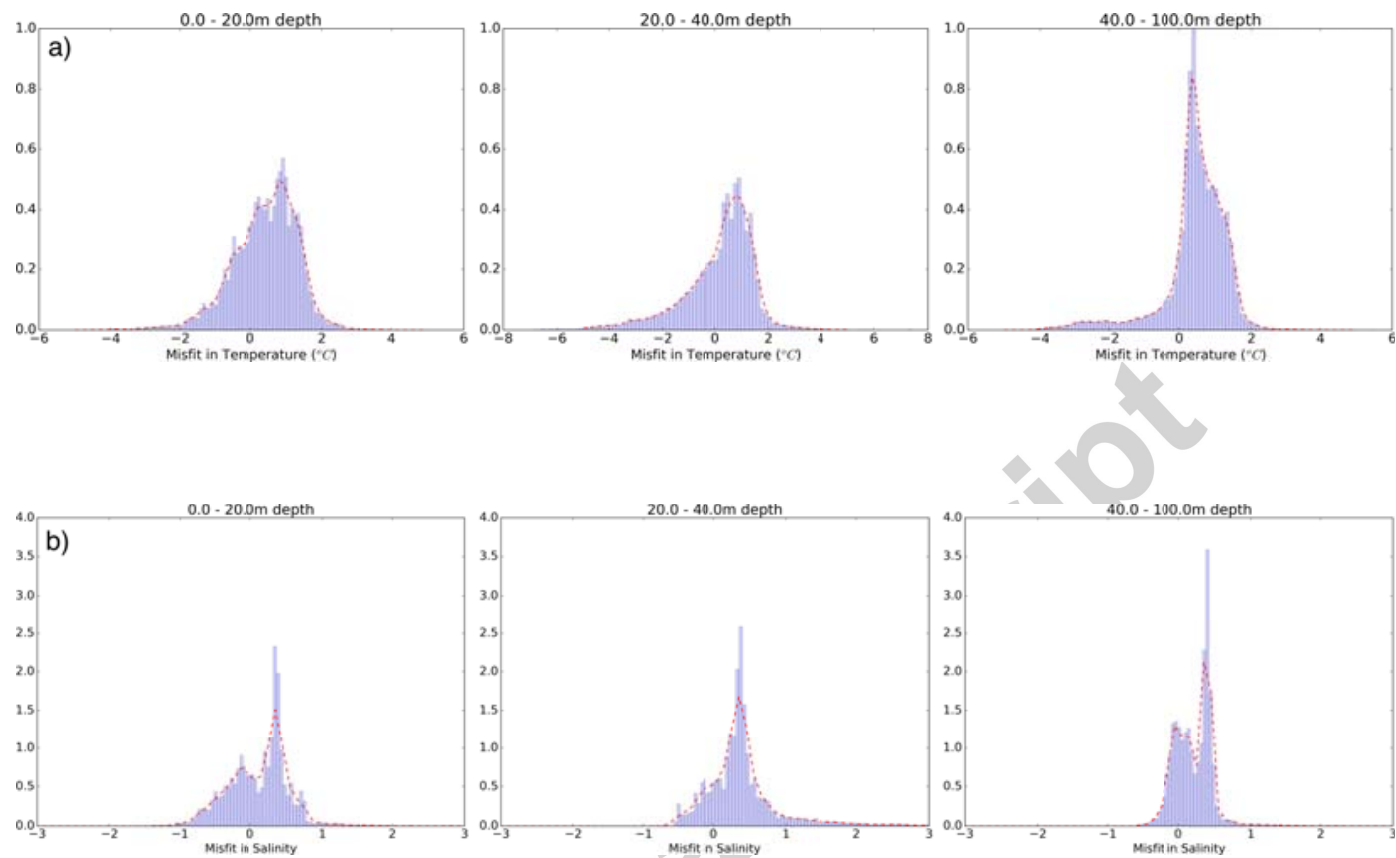

Figure 3: Normalized distribution of the misfit (modeled - observed) in a) temperature and b) salinity from RECOPESCA in situ profiles (only for profiles deeper than $100 \mathrm{~m}$ ) for three vertical layers: 0-20 m depth (left), 20-40 m depth (middle), and 40-100 m depth (right).

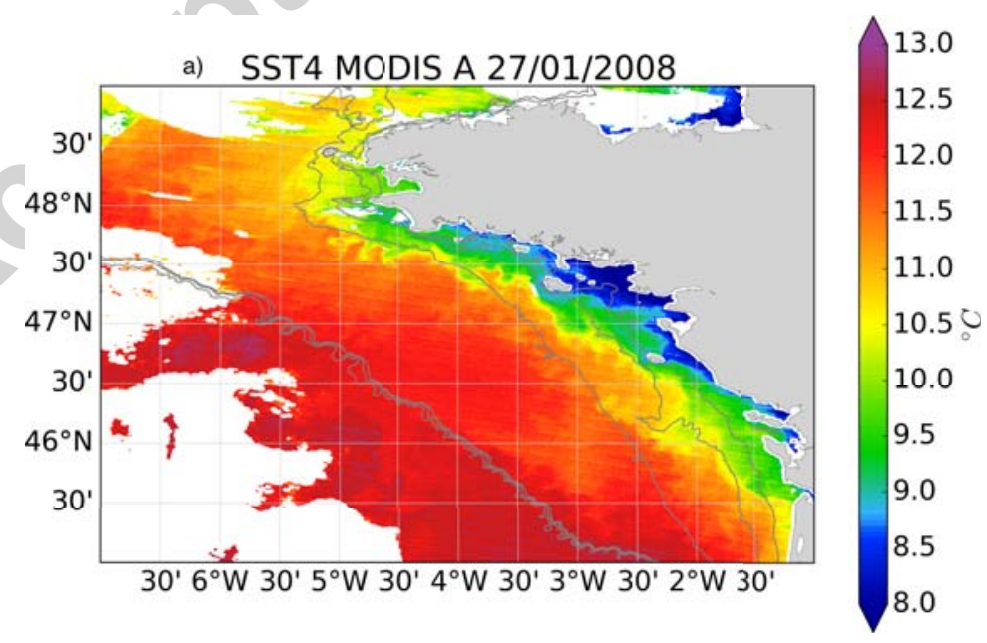



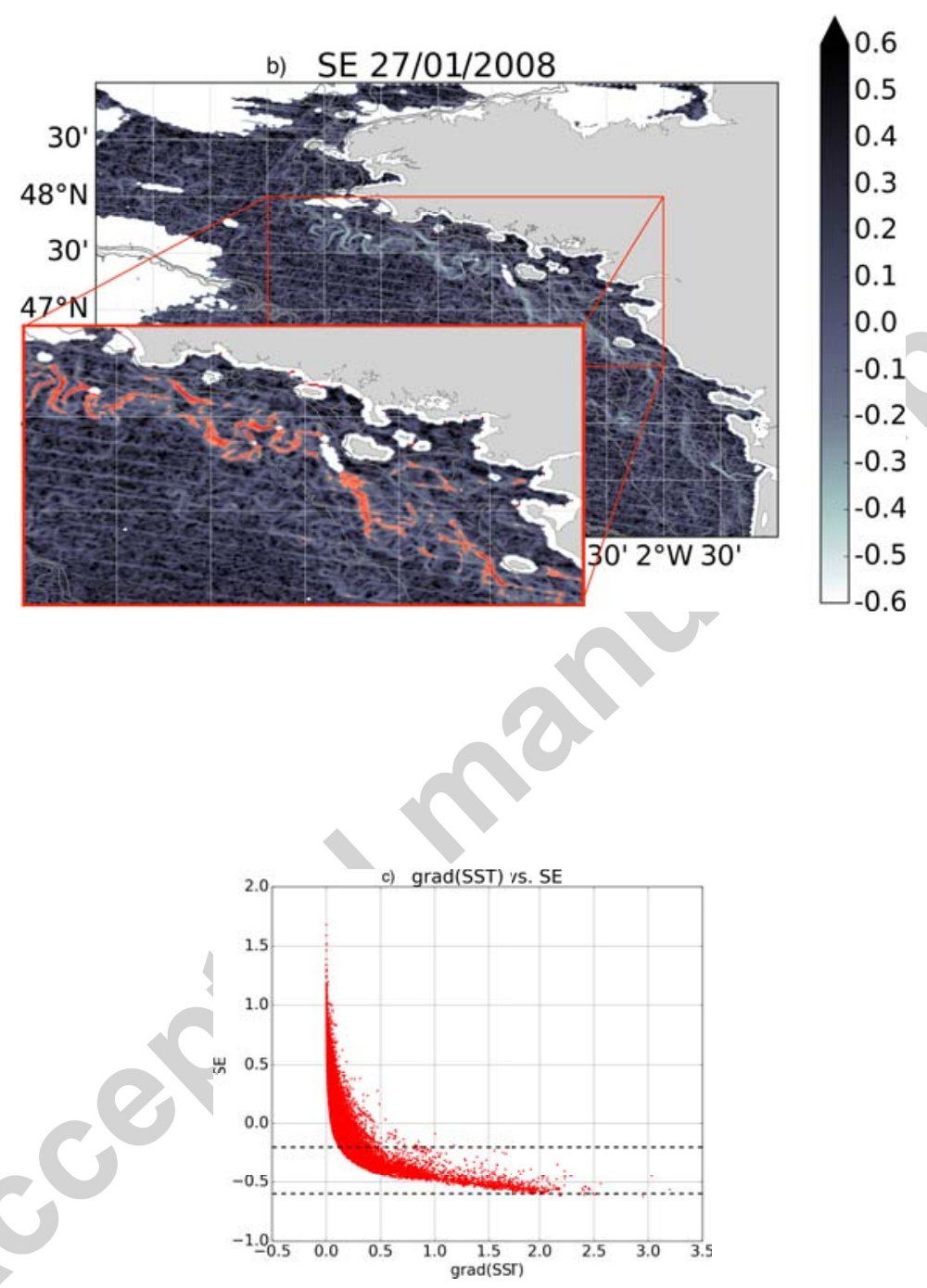

Figure 4: An example of a) remotely sensed sea surface temperature, b) the corresponding singularity exponent field (zoom: selected frontal pixels in red), c) gradient magnitude of the remotely sensed sea surface temperature versus the corresponding singularity exponent (area between the dashed lines is the range of frontal pixel selection) on 27/01/2008 (isolines represent the $30,50,100,200,250$ and $500 \mathrm{~m}$ depths). 
a) MODIS SST JFM 2003-2013

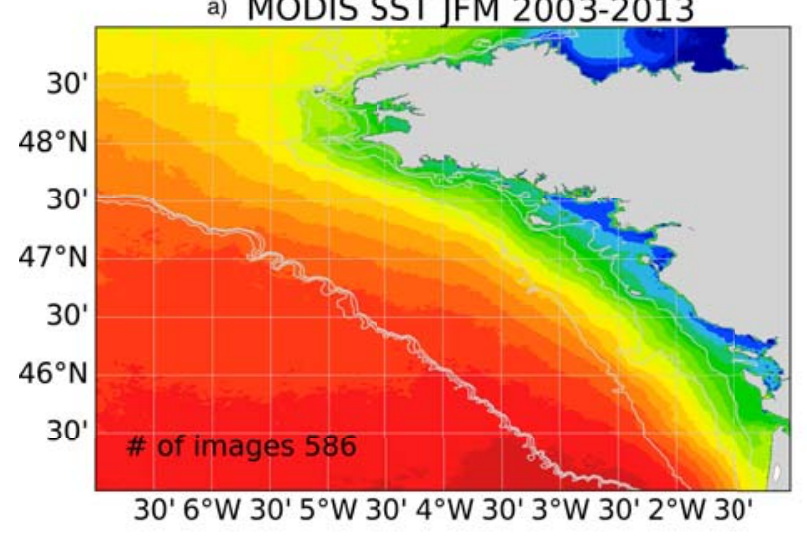

13.0

12.5

12.25

12.0

11.75

11.25

11.0

10.75

10.5

10.25

10.0

9.5

9.0

8.75

8.5

8.25

8.0

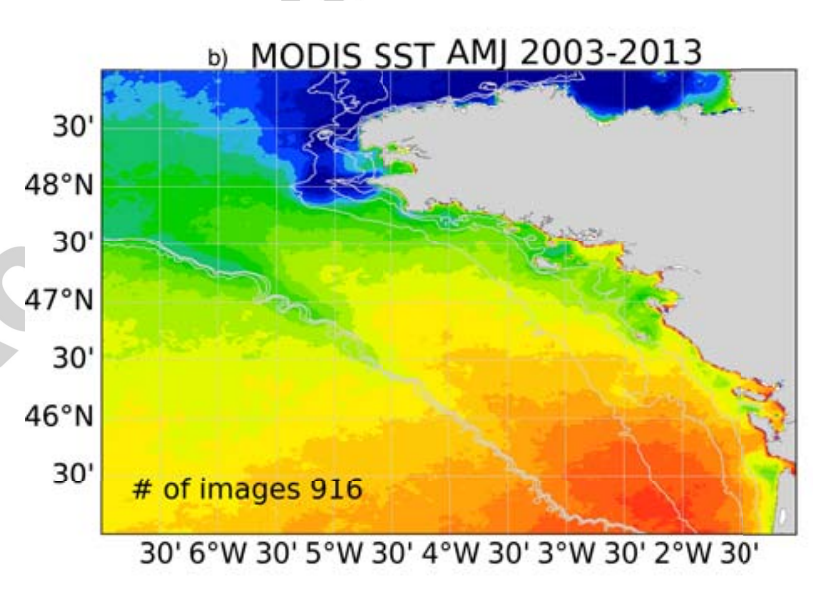

17.0

16.75

16.5

16.25

15.75

15.5

15.25

15.0

14.75

14.5

14.0

13.75

13.5

12.75

12.5

12.25

12.0 

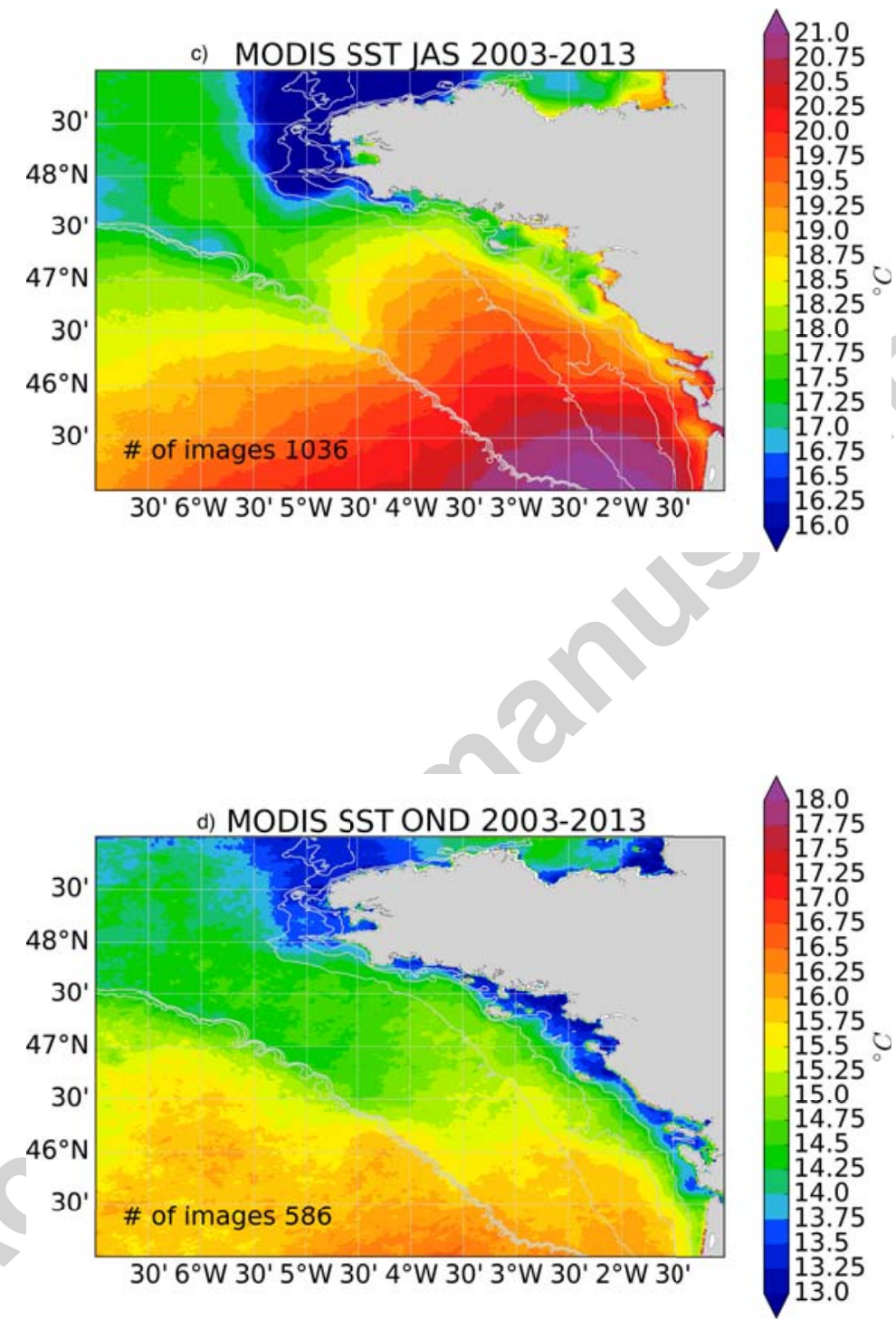

Figure 5: Seasonally averaged remotely sensed sea surface temperature from 2003 to 2013 over a) winter (January, February, March), b) spring (April, May, June), c) summer (July, August, September), and d) autumn (October, November, December). Colorscales differ for each panel, but range by schematically $5^{\circ} \mathrm{C}$. 

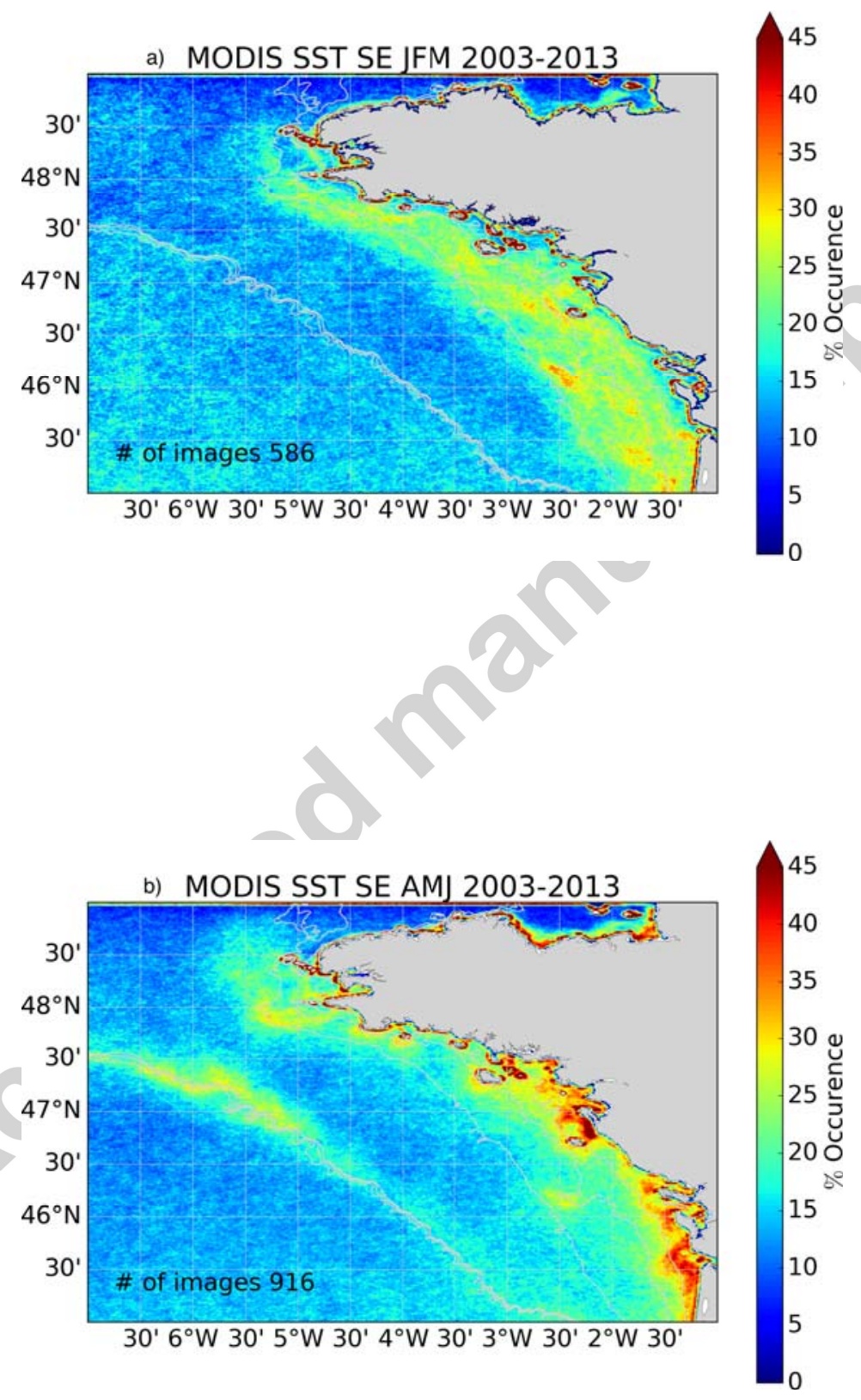

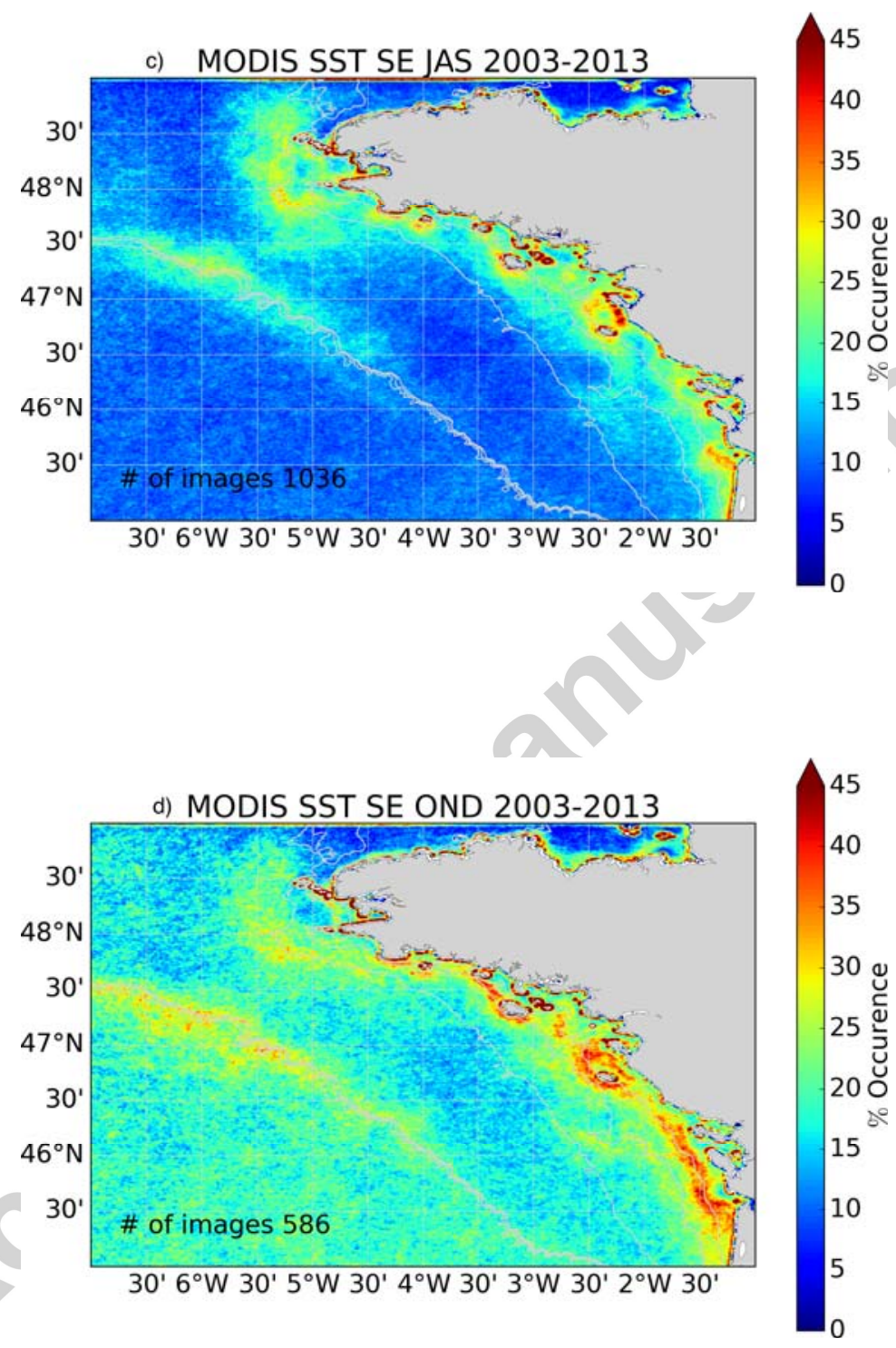

Figure 6: Front occurrence frequency of the MODIS remotely sensed sea surface temperature expressed in percentage of number of times a pixel is cloud-free from 2003 to 2013 in a) winter (January, February, March), b) spring (April, May, June), c) summer (July, August, September), and d) autumn (October, November, December) expressed in percentage of number of times a pixel is cloud-free. 


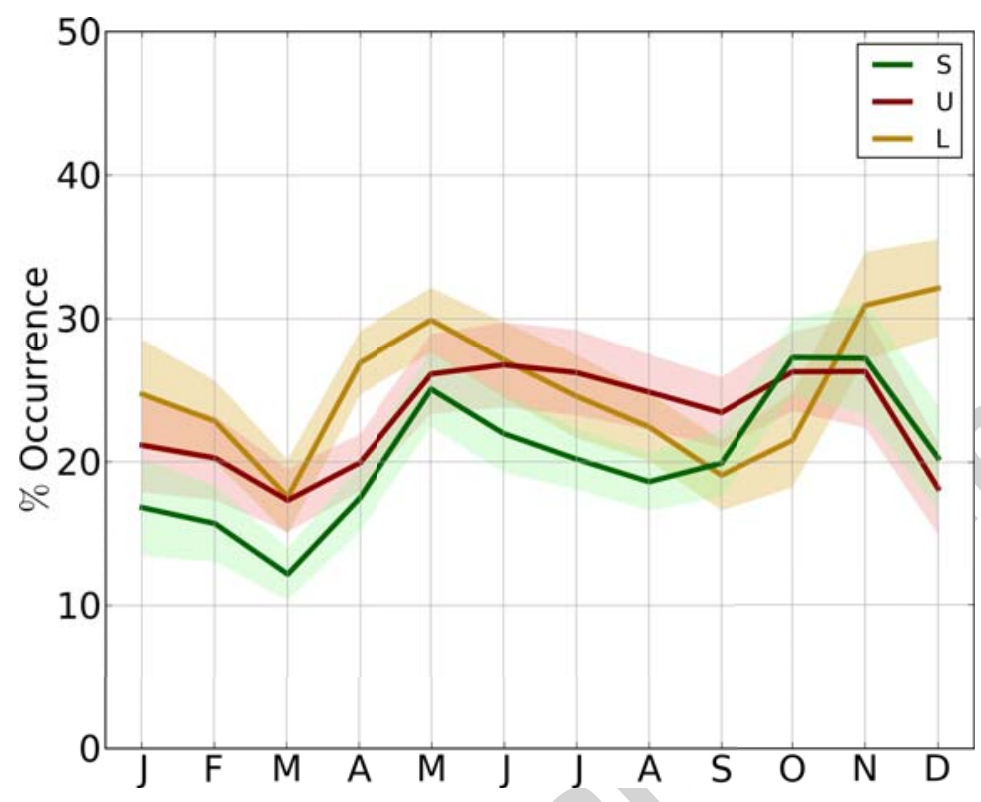

Figure 7: Observed monthly averaged front occurrence frequency in each of the regions defined in Figure 1. Error represents one standard deviation centered around the average.

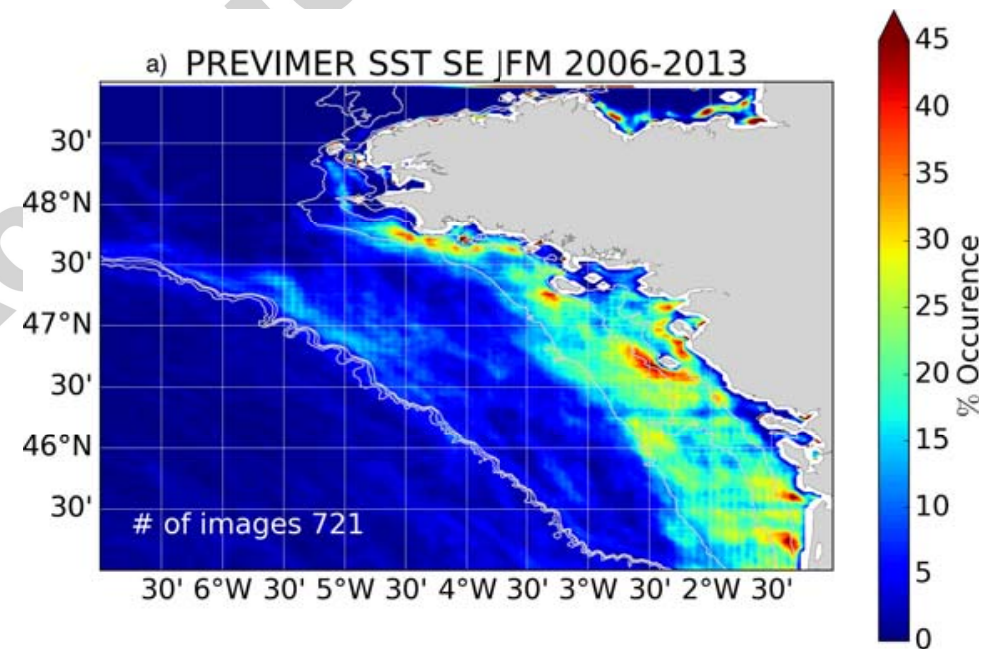


b) PREVIMER SST SE AMJ 2006-2013
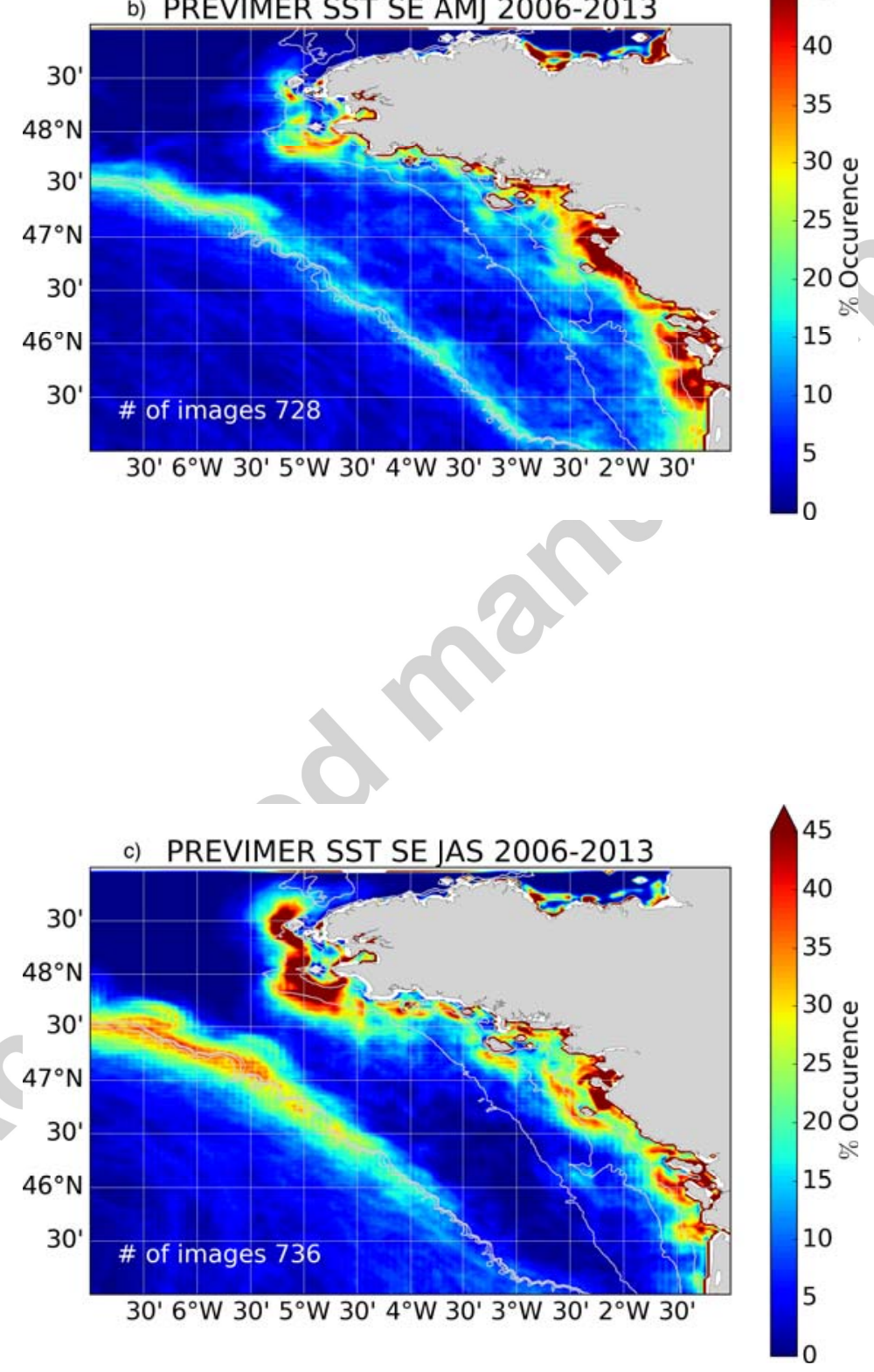


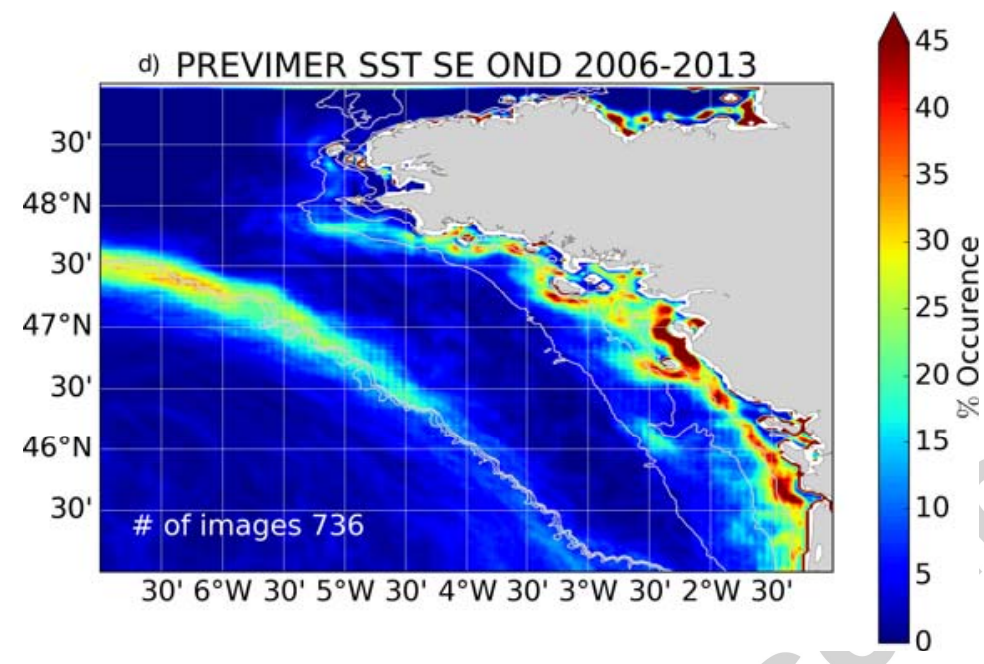

Figure 8: Front occurrence frequency of the modeled sea surface temperature expressed in percentage of number of times a pixel is cloud-free from 2006 to 2013 in a) winter (January, February, March), b) spring (April, May, June), c) summer (July, August, September), and d) autumn (October, November, December).

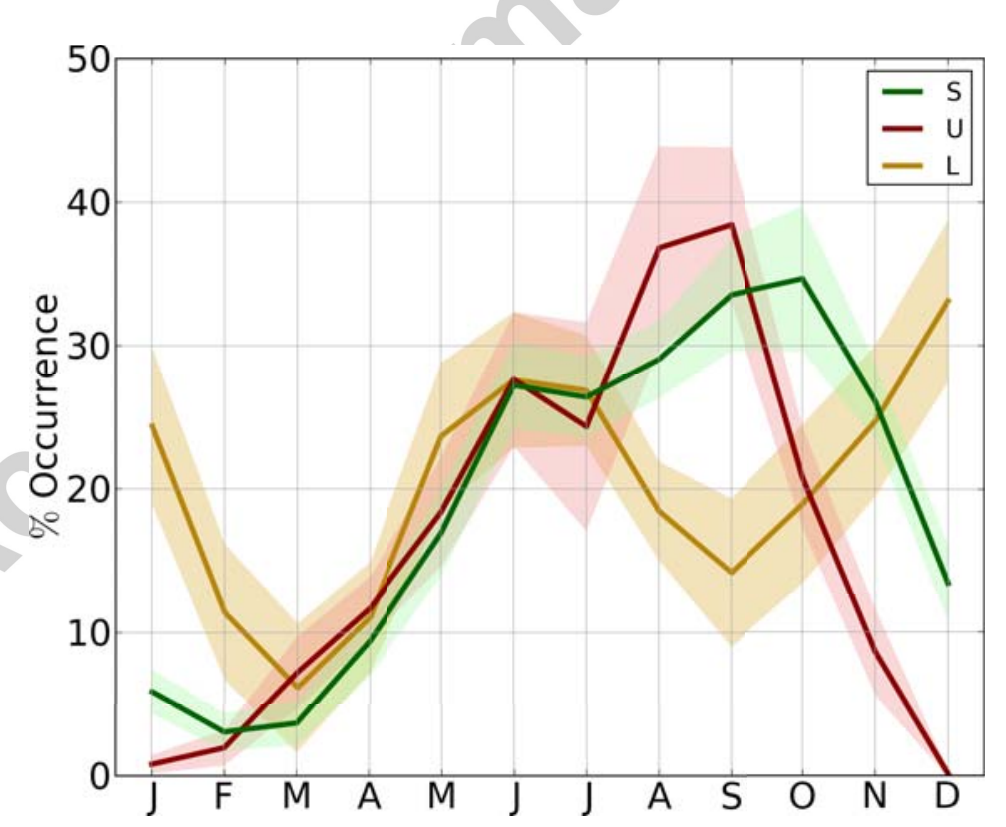

Figure 9: Monthly averaged front occurrence frequency in each of the regions defined in Figure 1. Error bars represent one standard deviation centered around the average. 

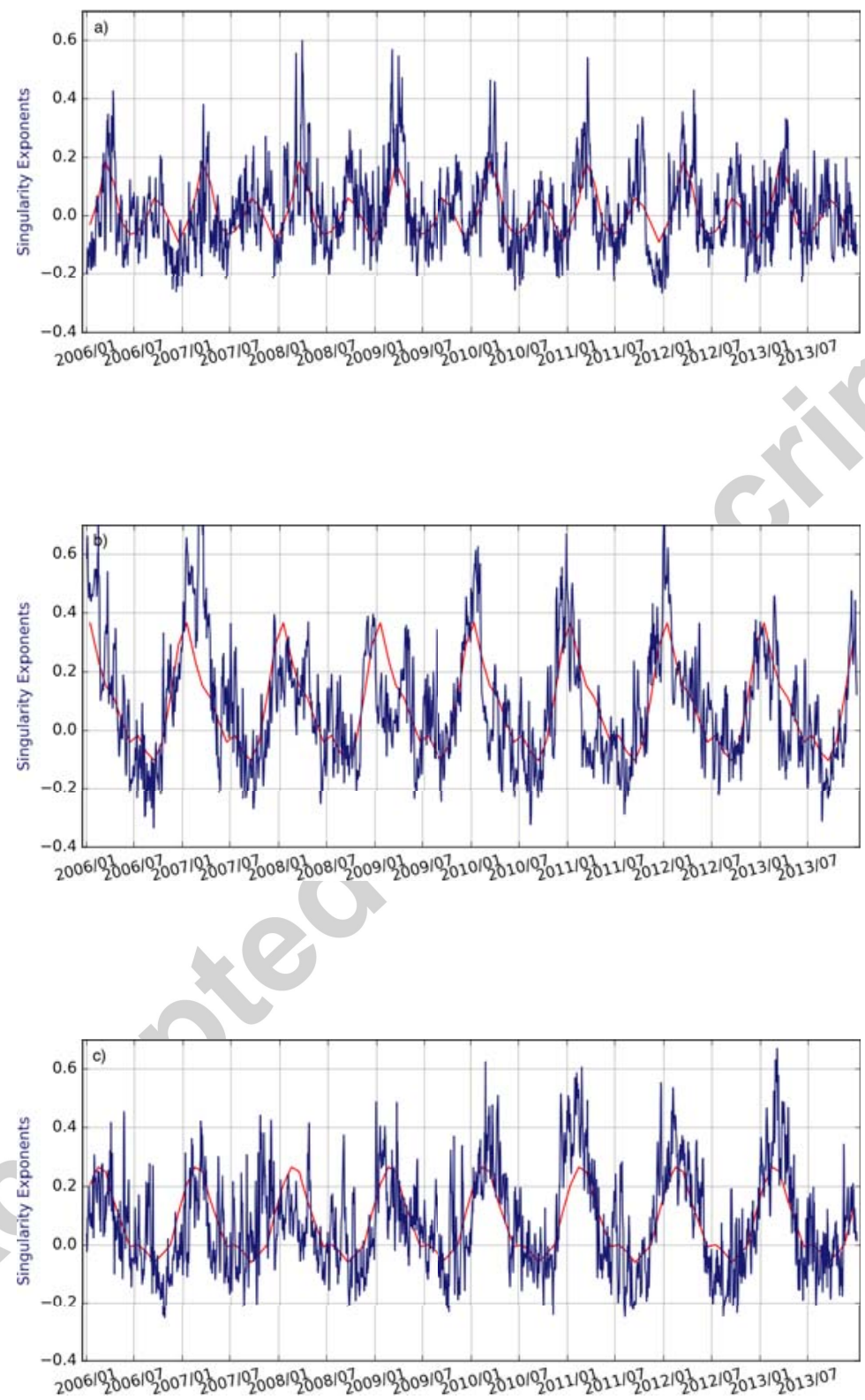

Figure 10: Singularity exponents of sea surface temperature (blue) and its climatology (red) from PREVIMER model simulations averaged over box a) L, b) U, and c) S (Figure 1) from 2006 to 2013. 


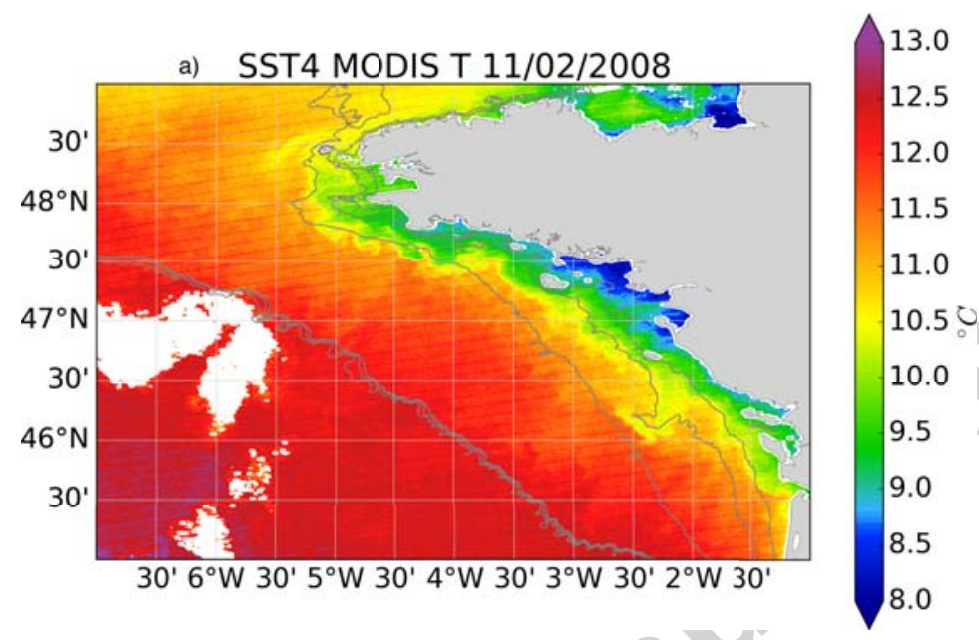

b) PREVIMER SST $11 / 02 / 2008$

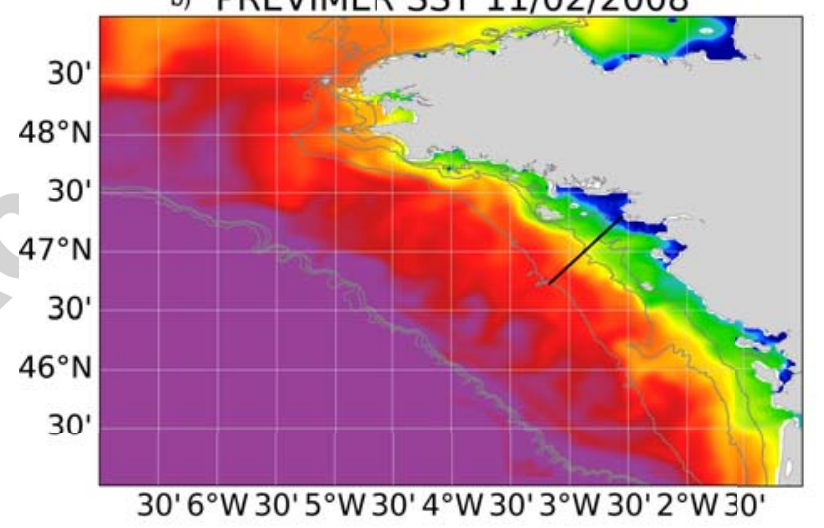

13.0

12.5

12.0

11.5

11.0

10.50

10.0

9.5

9.0

8.5

8.0 

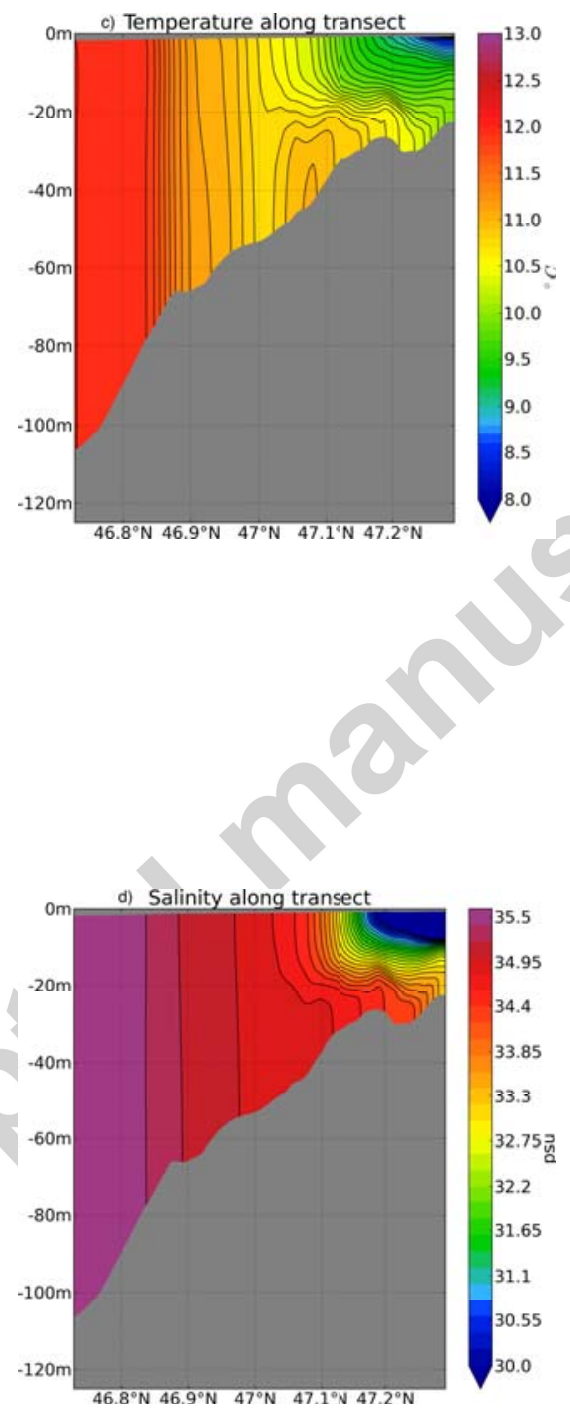

Figure 11: Remotely sensed sea surface temperature (a), modeled sea surface temperature (b), temperature (c) and salinity (d) along transect (black line on (b)) from the PREVIMER model simulations on 11/02/2008. 


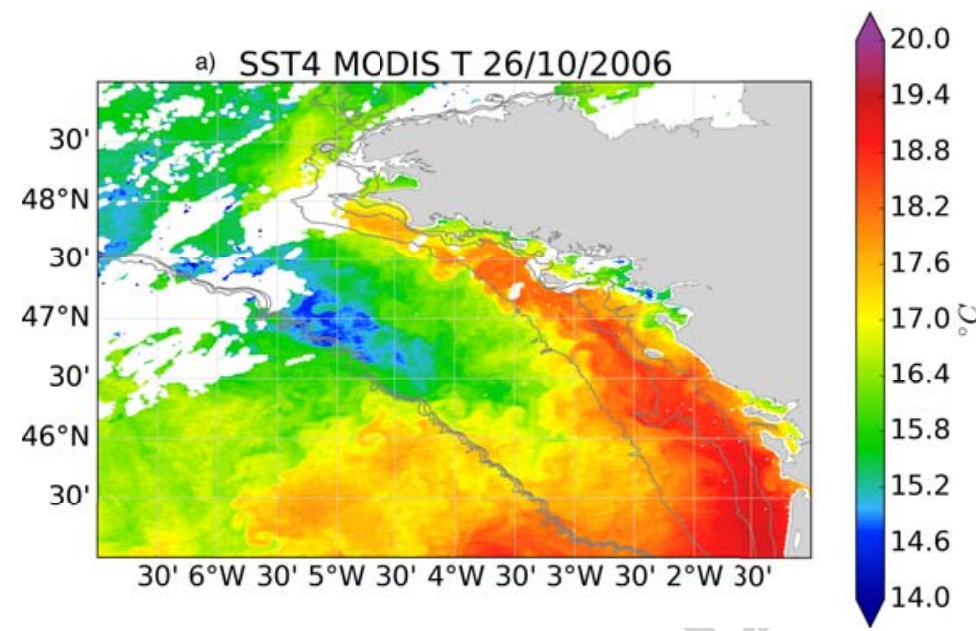

b) PREVIMER SST $26 / 10 / 2006$

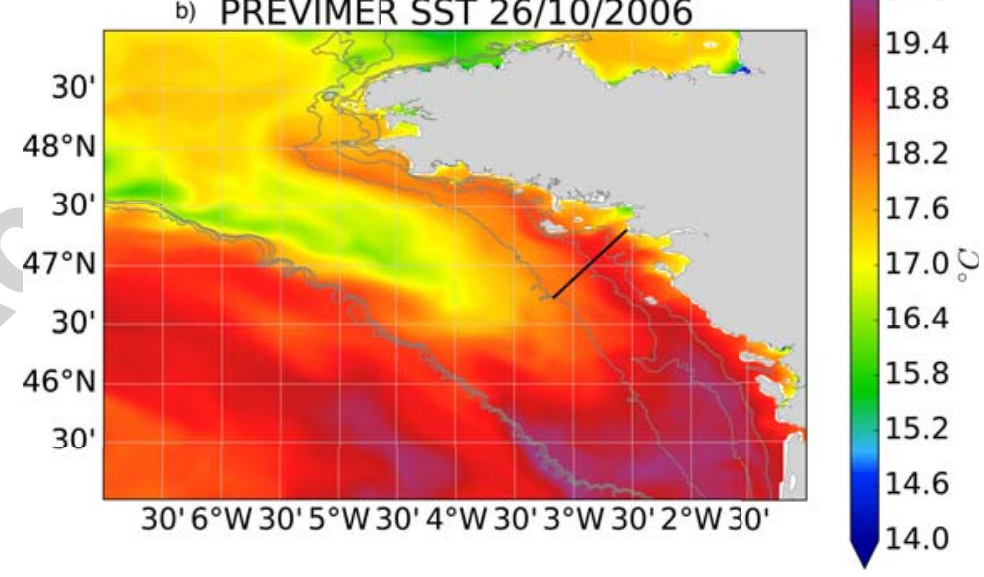



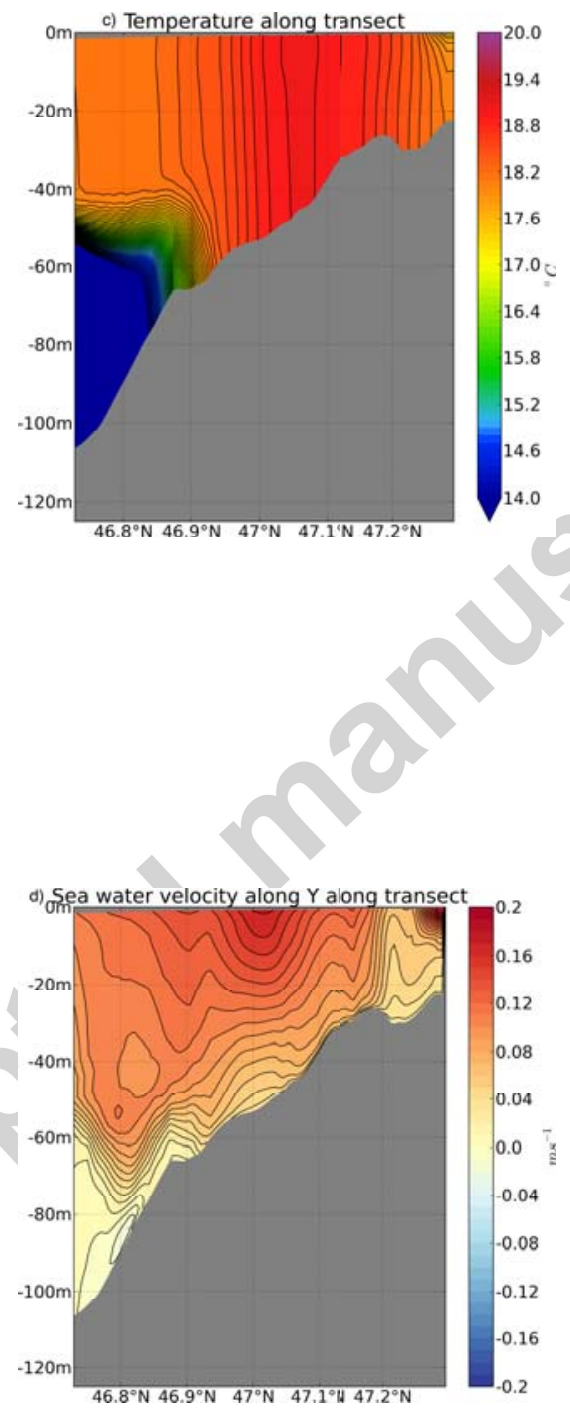

Figure 12: Remotely sensed sea surface temperature (a), modeled sea surface temperature (b), temperature (c) and meridional velocity (d) along transect (black line on (b)) from the PREVIMER model simulations on 26/10/2006. 


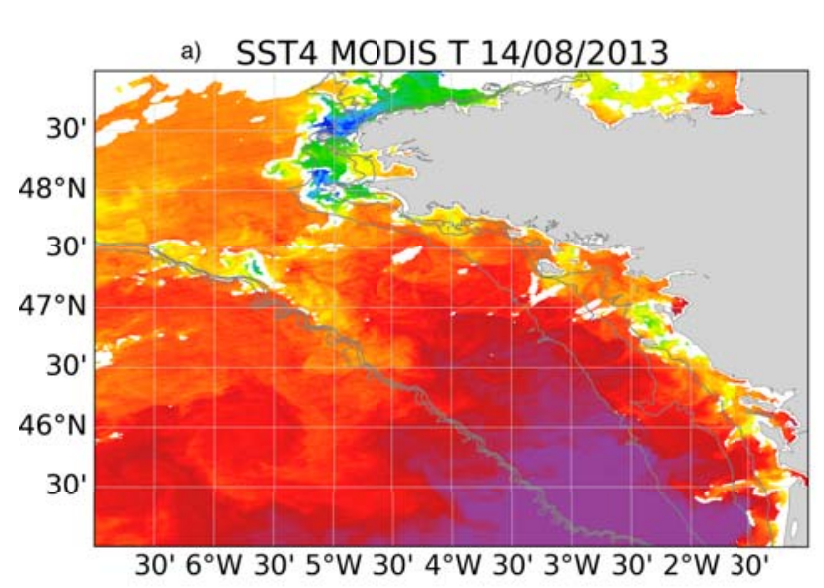

22.0

21.1

20.2

19.3

18.4

17.5 ○

16.6

15.7

14.8

13.9

13.0

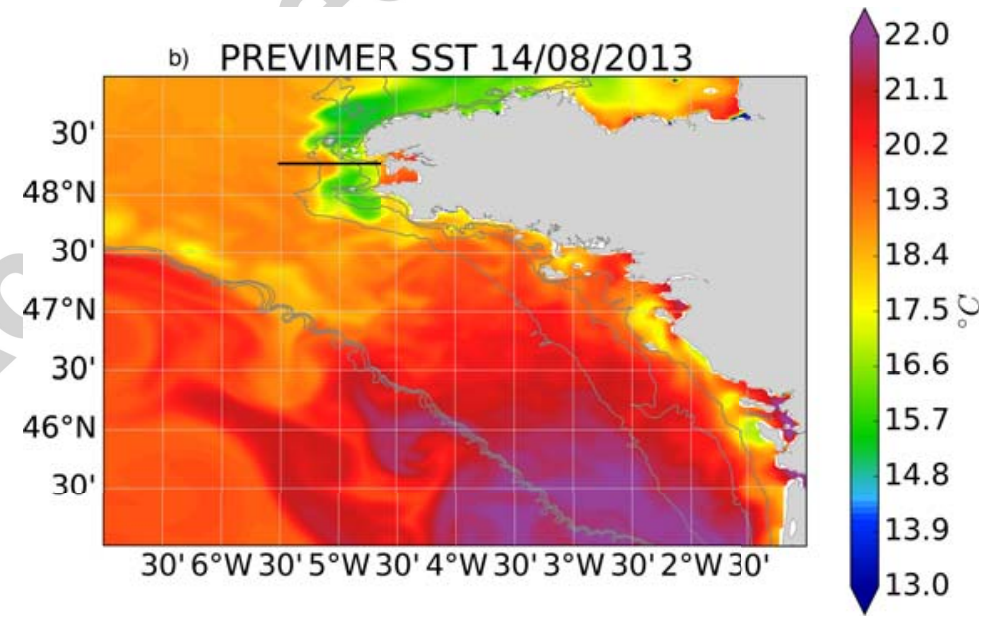




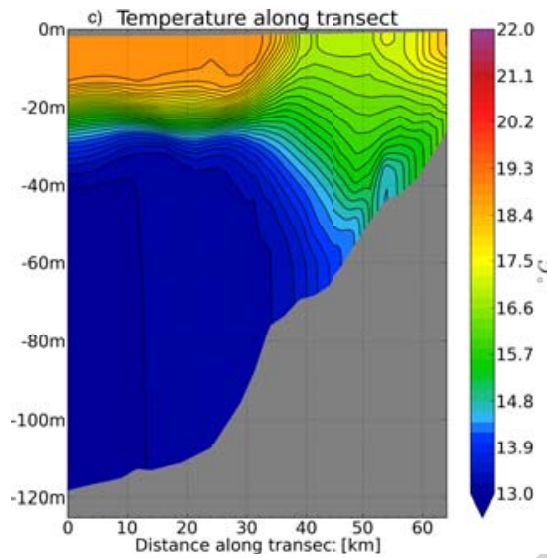

Figure 13: Remotely sensed sea surface temperature (a), modeled sea surface temperature (b), and temperature (c) along transect (black line on (b)) from the PREVIMER model simulations on $14 / 08 / 2013$.

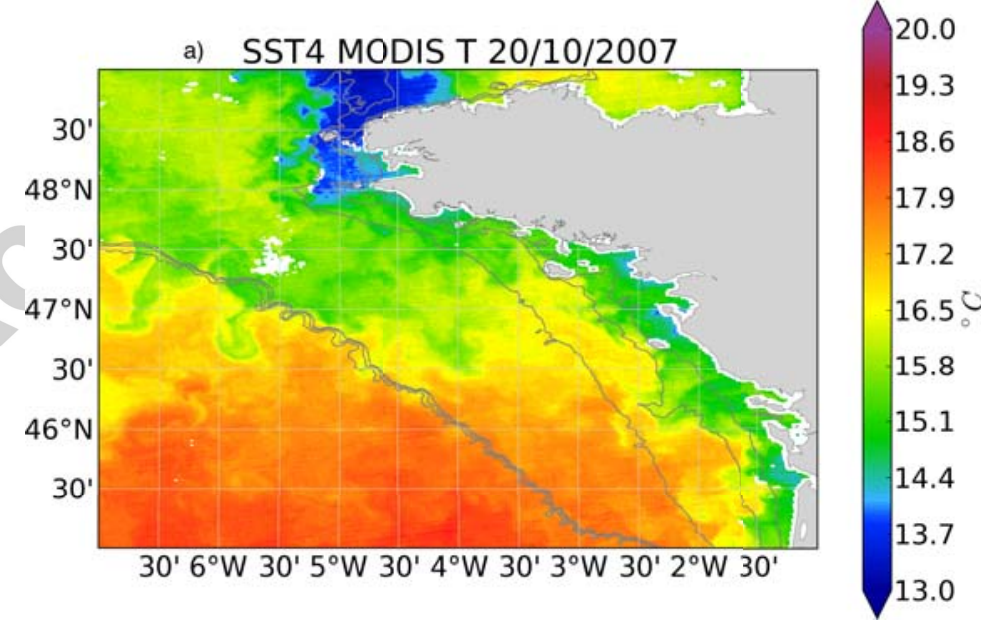



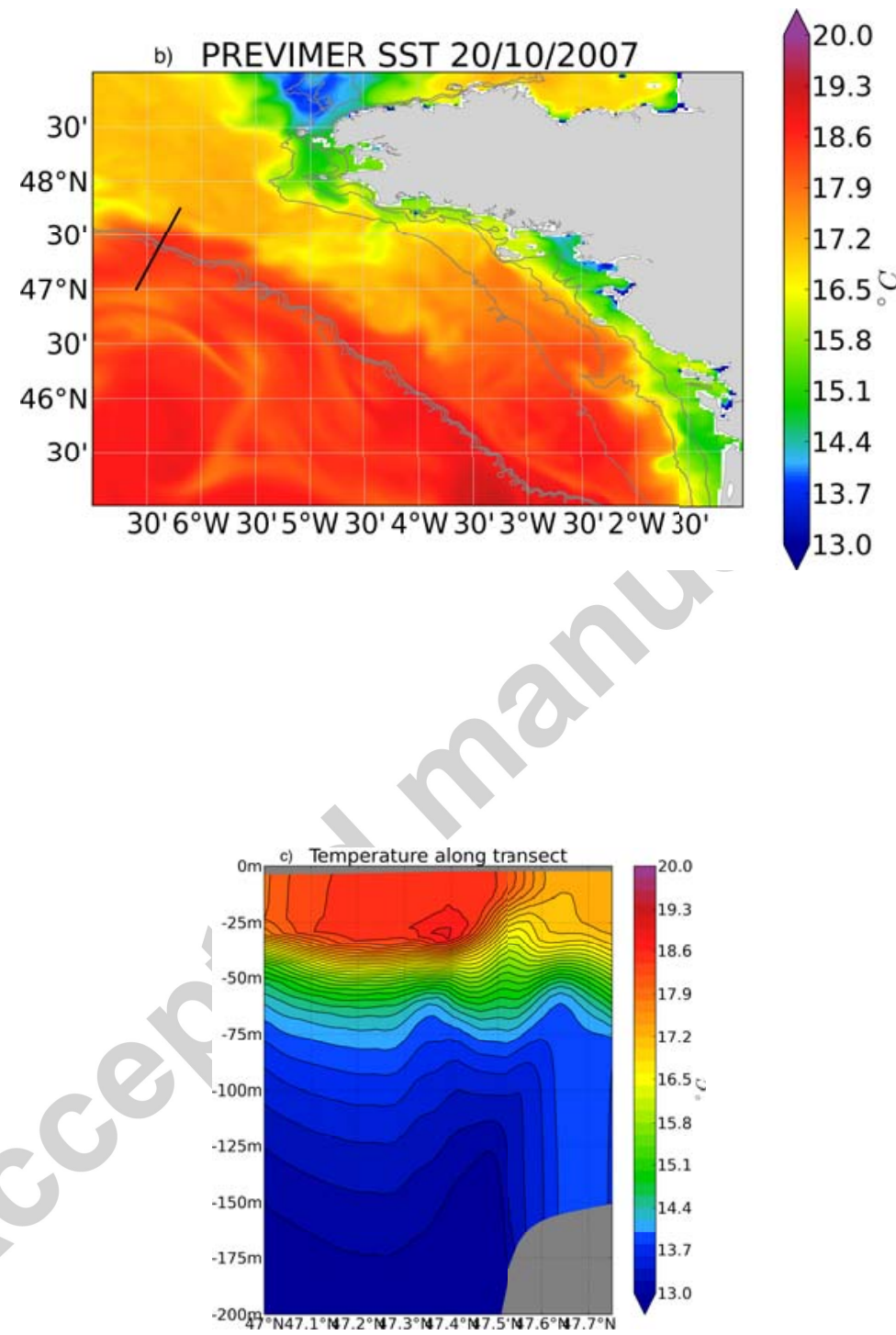

Figure 14: Remotely sensed sea surface temperature (a), modeled sea surface temperature (b), and temperature (c) along transect (black line on (b)) from the PREVIMER model simulations on $20 / 10 / 2007$. 